\title{
The Factor Structure of Greek Personality Adjectives
}

\author{
Gerard Saucier \\ University of Oregon \\ Ioannis Tsaousis \\ University of the Aegean
}

\author{
Stelios Georgiades \\ McMaster University \\ Lewis R. Goldberg \\ Oregon Research Institute
}

\begin{abstract}
Personality descriptors - 3,302 adjectives - were extracted from a dictionary of the modern Greek language. Those terms with the highest frequency were administered to large samples in Greece to test the universality of the Big-Five dimensions of personality in comparison to alternative models. One- and 2 -factor structures were the most stable across variable selections and subsamples and replicated such structures found in previous studies. Among models with more moderate levels of replication, recently proposed 6- and 7-lexical-factor models were approximately as well replicated as the Big Five. An emic 6-factor structure showed relative stability; these factors were labeled Negative-Valence/Honesty, Agreeableness/Positive Affect, Prowess/Heroism, Introversion/Melancholia, Even Temper, and Conscientiousness.
\end{abstract}

Keywords: personality language factor structure

Greek, a member of the Indo-European language family, has for some 2,500 years been a language of international importance. Many terms in past and contemporary international scientific languages (e.g., medical, psychological) have their roots in Greek. Indeed, the first documented, highly systematic attempts to describe, analyze, and categorize human personality attributes were made by the ancient Greeks. During the 4th century BC, scholars like Aristotle and Theophrastus used the method of characterology in an attempt to classify human types using Greek descriptors.

This report reflects two broad aims. First, we seek to develop a scientific taxonomy of personality descriptors in the Greek language. By studying a language with the historical depth of Greek, we create opportunities for the discipline of personality psychology to track the history of personality lexicons, by comparing the modern Greek personality lexicon with the one found in classical works written by Homer, Plato, Aristotle, and others. Second, these studies address the universality of the Big Five dimensions of personality in comparison with alternative competitor models.

Gerard Saucier, Department of Psychology, University of Oregon; Stelios Georgiades, Offord Centre for Child Studies, McMaster University, Hamilton, Ontario, Canada; Ioannis Tsaousis, Department of Preschool Education and Educational Design, University of the Aegean, Rhodes, Greece; Lewis R. Goldberg, Oregon Research Institute, Eugene, Oregon.

Work on this article was supported by Grant MH-49227 from the National Institute of Mental Health, U.S. Public Health Service. We are grateful to Michael C. Ashton, Vassilis Saroglou, and Auke Tellegen for useful suggestions on earlier versions of the article.

Correspondence concerning this article should be addressed to Gerard Saucier, Department of Psychology, 1227 University of Oregon, Eugene, OR 97403. E-mail: gsaucier@ darkwing.uoregon.edu

\section{The Lexical Approach}

Goldberg (1981), based on formulations by Allport and Odbert (1936) and by Cattell (1943), proposed a "lexical hypothesis," which states that the most important phenotypic attributes tend to become encoded as single words in the natural language. In addition, Goldberg (1981) argued that "the more important is an individual difference in human transactions, the more languages will have a term for it" (p. 142). The use of a dictionary for obtaining a comprehensive list of important personality descriptors is known today as the lexical approach.

The lexical approach has attracted the interest of researchers worldwide. Initial studies based on the lexical approach were conducted in languages of northern European origin: English (Goldberg, 1990), Dutch (De Raad, Hendriks, \& Hofstee, 1992), and German (Ostendorf, 1990). Subsequently, studies have been conducted in additional languages of European origin, including Hungarian (Szirmak \& De Raad, 1994), Italian (Caprara \& Perugini, 1994; Di Blas \& Forzi, 1998), French (Boies, Lee, Ashton, Pascal, \& Nicol, 2001), Spanish (Benet-Martínez \& Waller, 1997), Polish (Szarota, 1996), and Czech (Hrebickova, 1995). Moreover, a few studies have been conducted in non-European languages, including Turkish (Somer \& Goldberg, 1999), Hebrew (Almagor, Tellegen, \& Waller, 1995), Korean (Hahn, Lee, \& Ashton, 1999), and Filipino (Church, Katigbak, \& Reyes, 1998; Church, Reyes, Katigbak, \& Grimm, 1997). A detailed description and comparison of lexical studies can be found in a recent review by Saucier and Goldberg (2001).

\section{The Big Five and Alternative Models}

By an application of the lexical approach to American English, Goldberg (1990) arrived at an apparently robust five-factor solution that he named the Big Five. Similar factor structures had been found previously by other researchers (Norman, 1963; Tupes \& 
Christal, 1961). The Big Five are usually labeled as Extraversion (vs. Introversion), Agreeableness (vs. Disagreeableness), Conscientiousness (vs. Undependability), Emotional Stability (vs. Neuroticism), and Intellect (or Imagination or Openness to Experience). The Big Five provides a set of robust dimensions that describe, with a combination of parsimony and comprehensiveness, major phenotypical individual differences (Digman, 1990; Goldberg, 1993; John, 1990).

However, although the Big Five were spawned in lexical studies, lexical studies have only partially replicated the Big Five across languages, samples, and methodologies. When the "emic" structure of each language is derived via exploratory factor analysis, only about half of the relevant lexical studies have actually found the Big Five where one would expect, in the five-factor solution (Saucier \& Goldberg, 2001). Moreover, it has been demonstrated that the Big Five is contingent on a variable-selection strategy that concentrates on the terms most clearly interpretable as "stable dispositions," while eliminating terms that are highly evaluative or that refer to emotional states or aspects of attractiveness or physical appearance (Saucier, 1997).

Of course, one could conceivably define "cross-cultural replicability" by a lenient criterion, that is, claiming universality for any questionnaire structure that holds together when a set of questionnaire items is translated into some new language and confirmatory, Procrustean factor analytic methods are used (McCrae \& Costa, 1997). However, any of a number of structures might be robust under such an approach. Lexical studies, with their more stringent criterion for replicability, have better revealed the limitations of the five-factor approach.

One alternative lexical model has been derived by focusing on six-factor solutions, whether or not the language in question led to a Big-Five structure, while maintaining the narrower stabledisposition-focused variable-selection approach. Ashton et al. (2004) pointed out that in a majority of the lexical studies that they consider relevant, six-factor solutions have shown a consistent pattern: Conscientiousness and Intellect factors tend to be slightly but not greatly different from their Big-Five counterparts, Extraversion is replaced by a factor emphasizing sociability, Agreeableness by a variant emphasizing good-naturedness versus irritability, and Emotional Stability by a factor emphasizing self-confidence and toughness versus emotional vulnerability. The sixth factor involves honesty and humility at one pole and deceit and egotism at the other.

Three other alternative models involve seven factors. Each was developed by allowing a wider variable selection, including temporary states, highly evaluative terms, and in some cases, appearance descriptors. Tellegen and Waller's (1987) study of English descriptors found seven factors, including variants of the Big Five alongside two additional factors: Negative Valence (e.g., awful, terrible) and Positive Valence (e.g., outstanding, impressive). Follow-up studies, with similar methodology, of Spanish (BenetMartínez \& Waller, 1997) and Hebrew (Almagor et al., 1995) descriptors partly replicated this "Big Seven" structure. Studies of Turkish descriptors that used wide variable-selection criteria (Goldberg \& Somer, 2000) led to a structure featuring the Big-Five structure with an Intellect factor emphasizing nontraditionalism, plus Negative Valence and Attractiveness; this structure resembles a seven-factor structure found earlier in English (Saucier, 1997).
Both of these structures could be called "Big Five Plus Two" structures.

The structure found by Saucier (2003a), however, is not Big Five Plus Two. He showed that the seven-factor structures found in the earlier studies of Hebrew and Filipino were in fact rather close likenesses of one another and that this "Multi-Language Seven" (ML7) structure resembled seven-factor structures found in analyses of Italian and English descriptors. This structure corresponds rather well to the six-factor structure of Ashton et al (2004), with the exception that instead of the Honesty/Humility factor one finds two factors: a Negative Valence factor emphasizing socially unacceptable attributes (e.g., untrustworthy, crazy, stupid) and a Concern for Others versus Egotism factor. Honesty appears to be more highly associated with Negative Valence, and Humility with Concern for Others.

One possibility is that structures at the five-, six-, and sevenfactor levels are highly variant from one study to another, and cross-cultural ubiquity will be found only for structures that are more parsimonious. Several lexical studies have reported evidence about factor solutions containing only one factor (Boies, Lee, Ashton, Pascal, \& Nicol, 2001; Di Blas \& Forzi, 1999; Goldberg \& Somer, 2000; Saucier, 1997, 2003b). The findings from these studies have been quite consistent: The single unrotated factor contrasts a heterogeneous mix of desirable attributes at one pole with a mix of undesirable attributes at the other and can be labeled Evaluation. Indeed, in judgments about the meanings of diverse objects in a wide array of cultural settings, a global evaluation factor (good vs. bad) was typically found to be the single largest factor (Osgood, May, \& Miron, 1975).

Two-factor solutions from several lexical studies also suggest a consistent pattern: One factor includes attributes associated with positively valued dynamic qualities and individual ascendancy, whereas the other factor includes attributes associated with socialization, social propriety, solidarity, and community cohesion (Boies et al., 2001; Caprara, Barbaranelli, \& Zimbardo, 1997; Di Blas \& Forzi, 1999; Digman, 1997; Goldberg \& Somer, 2000; Hřebíčková, Ostendorf, Osecká, \& Čermák, 1999; Paulhus \& John, 1998; Saucier, 1997, 2003b; Shweder, 1972; White, 1980). These two factors may be aligned with some of the other sets of dual personological constructs reviewed by Digman (1997) and by Paulhus and John (1998), including Hogan's (1983) distinction between "getting ahead" (Dynamism; D) and "getting along" (Social Propriety; S). This constellation of two factors is also related to the three most ubiquitous dimensions of affective meaning, which include Potency (or Strength) and Activity in addition to Evaluation (Osgood et al., 1975); Osgood et al. (1975) indicated that in judgments of human targets Potency and Activity often combine in a blend they called Dynamism. DeYoung, Peterson, and Higgins (2002) have hypothesized that two broad, higher order personality factors identified with Digman's (1997) are best labeled as Stability and Plasticity, the first concerned with motivational and emotional regulation, the second with novelty and incentive reward. Given the letters $S$ and $D$ applied to these factors above, it is felicitous that these authors relate the Stability (Social Propriety) factor to serotonergic function and the Plasticity (Dynamism) factor to dopaminergic function.

Ironically, even though the first systematic attempts to describe human personality were made by Greeks, there has been no scientific taxonomy of personality descriptors in the contemporary 
Greek language. The present studies of Greek descriptors come at a critical juncture, when there is a need for studies to compare the replicability of Big-Five structures with alternative competitor structures. To build the basis for such comparisons, however, one needs a carefully developed collection of the most important person descriptors in the language. Studies 1 through 3 involved the refinement of such a collection of key variables. In Study 4, we derived an emic Greek factor structure from these variables and compared this structure to the Big Five and alternative models.

\section{Study 1: Extraction of Descriptors From the Lexicon}

We used a modified version of the methodology outlined by Angleitner, Ostendorf, and John (1990). First, three judges examined the newest edition of the Greek dictionary titled $\Lambda \varepsilon \xi \iota \kappa o ́ \nu \tau \eta \varsigma$

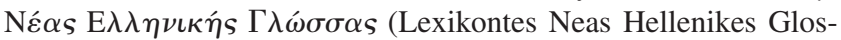
sas; Babiniotis, 1998), extracting all adjectives that might potentially be personality relevant. This dictionary is about 2,000 pages in length and contains some 150,000 separate entries. The three judges included Stelios Georgiades and Ioannis Tsaousis, as well as a third independent judge - a research assistant with a university degree. Ioannis Tsaousis examined the entire dictionary, whereas Stelios Georgiades and the research assistant each went through a complementary half of the dictionary. All adjectives selected by any of the judges were included in the initial list.

Judges were instructed to extract all adjectives that they considered personality relevant on the basis of a set of criteria. The criteria stated that the term should fit into a sentence such as "How [adjective] am I?"; excluded should be terms in any of four categories: (a) nondistinctive and applicable to all individuals (e.g., human, born); (b) referring to geographical origin (e.g., Athenian), to nationality (e.g., Greek), or to professional- or job-related identities (e.g., physician, student); (c) referring to only a part of the person (e.g., shining eyes); or (d) having personality implications that are both metaphorical and tenuous (e.g., mouse, rose). Instructions were given in English, as all judges were fluent in English, but the example terms were Greek. The Greek equivalents for the examples mouse, rose, physician, and student were (like many but not all Greek modifiers) simultaneously adjectives and nouns (as are the words Athenian and Greek in English).

A comprehensive set of 3,302 potentially personality-relevant adjectives was collected. This set included about $2.2 \%$ of the total entries in the dictionary. However, a good number of these terms appeared to be familiar to only a minority of Greek-language speakers, and many others appeared to be unclear and ambiguous in meaning. A common second step in most lexical studies has been the culling of the most unfamiliar and ambiguous terms.

\section{Study 2: Initial Ratings of Clarity of Meaning}

In this study, a new set of judges rated the adjectives on the list developed in Study 1, with respect to the adjective's clarity of meaning. Of the seven judges, four were university graduates and three were current university students. Each judge provided a rating on each of the 3,302 terms from Study 1. Clarity of meaning was rated on a 3-point scale ranging from 1 (the meaning of the word is not clear to me) to 2 (the meaning of the word became clear after giving it some thought) to 3 (the meaning of the word is fairly clear to me). Selected terms were those that obtained the highest rating (3) from at least four of the seven judges.

On the basis of this criterion, 857 adjectives were omitted from consideration, leaving 2,245 adjectives on our list. These terms were all apparently relatively clear in meaning, but we expected them to differ substantially in their frequency of use. Because we were interested in selecting a set of most commonly used adjectives, we proceeded to a third step, obtaining ratings of the adjective's frequency of use.

\section{Study 3: Further Ratings of Clarity and Familiarity}

One group of seven judges, community members who were not university students, rated the set of 2,245 adjectives that were derived from Study 2. They used a 4-point rating scale; the first three steps were identical to those used in Study 2, but a further step, 4 (the meaning of the word is perfectly clear to me) was added to the rating scale.

A second group of seven judges-university students-also rated the set of 2,245 adjectives from Study 2. These judges rated the degree to which they believed the adjective was frequently used for the description of a person. Ratings were on a 5-point scale: 1 (this word is never used for the description of a person) through 2 (this word is rarely used for the description of a person), 3 (this word is sometimes used for the description of a person), 4 (this word is often used for the description of a person), and 5 (this word is extremely often used for the description of a person).

In either task, terms were retained for further study if they received a rating of 3 or more from a majority (at least four of seven) of judges. Average clarity ratings and frequency ratings correlated .61, with 11 of the top 20 for clarity also being in the top 20 for frequency. The 20 terms with highest frequency ratings could be translated as decisive, calm/cool, mature, decent, optimistic, and independent (favorable attributes), and rude, anxious, unjust, insensitive, pessimistic, selfish, nervous, cunning, clumsy, antisocial, wild, disrespectful, irresponsible, and immature (unfavorable attributes).

The adjectives were rank-ordered on the basis of their mean clarity-of-meaning rating in Study 3, and separately rank-ordered on the basis of their mean frequency-of-use rating in that study. Two hundred forty-eight terms appeared in both lists of 400 , but each of the two top-400 lists included 152 terms not in the other list. We considered all three variable selections-the 400 most frequent descriptors, the 400 highest clarity descriptors, and the 248 descriptors high on both - to be of interest and gathered data in Study 4 with each of three samples using one of these three sets of terms.

\section{Study 4: The Factor Structure of Greek Descriptors in Self-Ratings}

\section{Questionnaires and Participants}

In this study, we used three questionnaires. The 400 High Frequency Descriptors (400-HFD) included the top 400 Greek adjectives in terms of rated frequency of use. The 400 High-Clarity Descriptors (400-HCD) included the top 400 Greek adjectives in terms of rated clarity of meaning. The 248 High Clarity and 
Frequency Descriptors (248-HCFD) included the 248 terms appearing on both the 400-HFD and the 400-HCD.

We gathered self-ratings from three samples. Sample 1 included 991 participants (including at least 224 men and 751 women [some participants in each sample did not indicate their gender], mean age $=23.6$ years) who used the 400-HFD. Sample 2 included 429 participants (including at least 152 men and 274 women, mean age $=22.1$ years) who used the 400-HCD. Sample 3 included 538 participants (including at least 133 men and 369 women, mean age $=26.7$ years) who used the 248-HCFD. Because other, comparable lexical studies have most often used frequency of use as the main criterion for variable reduction, the analyses reported here utilize Sample 1 as the primary sample. Samples 2 and 3 are used to examine the effects of variable selection on factor structures. Research participants were students from the University of the Aegean (Rhodes), Panteion University (Athens), School of Paedogogical and Technical Education (Athens), and Aristoteleion University (Thessaloniki).

\section{Emic-Structure Factor Analyses}

One primary aim was to derive the best emic structure for Greek descriptors. This aim is exploratory and does not involve imposition of a priori structural hypotheses.

First, we examined whether the factor structures tended to differ on the basis of variable selection. That is, would the three questionnaires converge on a single factor structure? If they do, it would allow parsimony in data analysis, as one could justifiably aggregate all the data sets into a single one involving the 248 common terms. To determine whether the factor structures tended to differ on the basis of variable selection, controlling for the effects of participant sample, we focused on Samples 1 and 2. In Sample 1, principal-components solutions of 1 unrotated and 2 to 10 rotated factors were derived for both (a) the full set of 400 high-frequency terms and (b) the reduced set of 248 common terms, and factor scores for all solutions were retained. In Sample 2, principal-components solutions of 1 unrotated and 2 to 10 rotated factors were derived for both (a) the full set of 400 high-clarity terms and (b) the reduced set of 248 common terms, and factor scores for all solutions were retained. Then, within each sample, for each number of factors, we correlated the factor scores to determine the degree of convergence between the 400-HFD and the 248-HCFD and between the 400-HCD and the 248-HCFD. Finally, we compared the 400-HFD (Sample 1) and the 400-HCD (Sample 2) structures using coefficients of factor congruence based on the 248 common terms and compared each of these to the 248-HCFD structure-using congruence coefficients; a caveat is that this analysis compares not just differing variable selections but also differing participant samples, so that divergence could be due to sample as well as variable selection.

The same set of analyses were conducted with original data and with data that had been ipsatized - that is, row standardized so that each case had the same mean and standard deviation.

Ipsatization beneficially removes individual differences in use of the response scale (i.e., individual differences in mean and variance) from the data, and it is more likely to lead to bipolar factors. However, there is controversy over whether ipsatization is always appropriate. In a domain of variables whose response means are asymmetrically distributed, ipsatization can produce artifactual bipolarities (Dunlap \& Cornwell, 1994; ten Berge, 1999). Among frequently used natural-language person descriptors, balanced keying does not necessarily occur; as one example, there are far more words in English for negative affectivity than for its absence, therefore individual differences in response means will be confounded with reported negative-affectivity tendencies. Ipsatization is a partialing procedure, and in cases like this, it partials out some substance, not just style. If one examines only ipsatizeddata results, one will not understand the result of ipsatizing. Therefore, although we examined results using both original and ipsatized data, and used replication in ipsatized data as one useful criterion among many for evaluating factor structure, we gave greater emphasis to findings from the original data. (Readers interested in further information on the ipsatized-data factors from this study should consult Gerard Saucier or http://darkwing .uoregon.edu/ $\sim$ gsaucier/Greek_ipsatized_data_factors.htm.)

Our plan was to aggregate all three samples and use the 248 common terms for analysis if there were no differences due to variable selection, thereby achieving maximum sample size and, thus, statistical power. If, however, there were important differences in factor structure emerging from these analyses, we planned to develop factor structures for Greek descriptors primarily from the set of 400 high-frequency descriptors, so as to enhance comparability with previous studies. Many previous lexical studies have used frequency of use as a criterion for variable reduction; clarity has been used more sparingly as a criterion, with only extremely unclear terms sometimes removed. Either way, our plan was to choose the optimal hierarchical level (number of factors) based primarily on replication across subsamples.

\section{Hypotheses Involving Imposed-Etic Structures}

Another broad aim of this study was to test a variety of structural models derived from previous lexical studies. Each hypothesis posited a specific factor structure as represented in a set of factor markers selected from the 248-HCFD (in a few cases, terms from the 400-HFD or the 400-HCD were selected that were not in the 248-HCFD). A complete list of marker terms for each of the a priori factors is found in the Appendix.

A currently prevailing assumption is that variation in personality attributes occurs along five principal dimensions (i.e., the Big Five). Thus the following hypothesis has been predicted:

When five factors are extracted and rotated, Greek adjectives will yield a Big-Five structure.

Markers for the Big Five were developed by referring to the 100 Unipolar Markers (Goldberg, 1992), as well as the 3M40 (Saucier, 2002a; Saucier \& Goldberg, 2002), which includes a number of previously used Big-Five marker terms not found in Goldberg's 100 markers. English adjectives from these marker sets that were included among the English translations of the high frequency and clarity Greek terms were selected as factor markers. The adjectives from another Big-Five marker set-Greek translations of the adjectives in the Mini-Markers (Saucier, 1994) that were not among the highest in clarity or frequency (and thus already included) were appended to the other adjectives in each questionnaire. However, because we were concerned that some of these translations might use unclear or infrequent terms, hampering comparability 
with marker sets for other structures that would consist entirely of high clarity and high frequency adjectives, we used the additional translated Mini-Markers items only as a last-resort source of marker terms for candidate models.

Two lexical studies with inclusive variable selections found factors resembling the Big Five alongside two additional factorsNegative Valence and Attractiveness (Goldberg \& Somer, 2000; Saucier, 1997), which yielded another hypothesis: Big-Five Plus Two.

When seven factors are extracted and rotated, Greek adjectives will yield a structure including the Big Five plus Negative Valence and Attractiveness.

Negative Valence and Attractiveness marker terms were selected by finding high-loading terms from the two previous studies-one of Turkish and one of English-that also occurred in the Greek variable selections.

When seven factors are extracted and rotated, Greek adjectives will yield a structure corresponding to the "Big-Seven" structure.

This Big-Seven hypothesis was tested by referring to the 70 best terms in the Inventory of Personal Characteristics-7 (IPC-7), a set of marker adjectives for the Big Seven based on Tellegen and Waller's (1987) study of English descriptors; that study found variants of the Big Five alongside two additional factors: Negative Valence (e.g., awful, terrible) and Positive Valence (e.g., outstanding, impressive). The reduced set of 70 best IPC-7 terms was used previously as an imposed etic in a study of Spanish descriptors (Benet \& Waller, 1995). Adjectives found both in this set of 70 terms and in the Greek variable selections were selected as BigSeven markers.

As Saucier (2003a) pointed out, studies of personality descriptors in Filipino (Church et al., 1997) and Hebrew (Almagor, Tellegen, \& Waller, 1995) yielded surprisingly similar sevenfactor structures, a structure reasonably well-replicated in both Italian and English. Thus, yet another seven-factor hypothesis has been proposed:

When seven factors are extracted and rotated, Greek adjectives will yield factors interpretable as Gregariousness, SelfAssurance, Even Temper, Concern for Others, Conscientiousness, Intellect, and Social Unacceptability (or Negative Valence).

Markers for these factors were derived from Saucier's 2003a study as well as from adjective markers used in Saucier's 2003b study of English type nouns. A variant on this hypothesis involves these seven factors appearing with an eighth Attractiveness factor. Attractiveness was found in American data analyses to co-occur with the ML7 structure represented in the seven-factor hypothesis (Saucier, 2003a).

A six-factor hypothesis was based on the consistent pattern in six-factor solutions in many lexical studies (Ashton et al., 2004):

When six factors are extracted and rotated, Greek adjectives will yield factors interpretable as Extraversion/Sociability, Emotionality/Vulnerability, Agreeableness/Good-Naturedness,
Honesty/Humility, Conscientiousness, and Intellect/Unconventionality.

Markers for this six-factor structure were derived from Ashton et al.'s (2004) description of key traits for each factor, which was based on the terms (in English translation) that appear most frequently across numerous languages on each of these six recurrent factors.

There are indications that one- and two-factor models are more robust than the Big Five, both within and across languages (Saucier, 2002b), and these structures were recently found to replicate well in a study of English type nouns (Saucier, 2003b), whereas adjective structures with more factors did not. We tested a onefactor hypothesis:

When only one factor is extracted, Greek adjectives will yield a factor contrasting desirable and undesirable attributes.

We tested also a two-factor hypothesis:

When two factors are extracted and rotated, Greek adjectives will yield one factor related to Dynamism and another related to Morality/Social Propriety.

Markers for these factors were drawn from those English adjectives used as Big One and Big Two markers in the type-nouns study (Saucier, 2003b).

There have been proposals regarding the universality of a structure of three lexical factors (broader versions of Extraversion, Agreeableness, and Conscientiousness; Di Blas \& Forzi, 1999; Peabody \& De Raad, 2002; Saucier, 1997). Although some recent lexical studies (e.g., Boies et al., 2001; Church et al., 1997) have failed to confirm this structure at the three-factor level, nonetheless by testing the Big-Five markers for the factors with the emic Greek three-factor structure, we tested the hypothesis:

When three factors are extracted and rotated, Greek adjectives will yield factors related to Extraversion, Agreeableness, and Conscientiousness.

If the Big Three corresponds to the emic three-factor structure, these correlations should be quite high.

Another model of three personality factors includes Positive Emotionality, Negative Emotionality, and Constraint factors, Tellegen's (1985) Big Three. This model is rarely tested in lexical studies, because it has never appeared in a lexical study in unrestricted factor analyses. It is likely that its failure to appear in lexical studies is due to the heavy representation in the lexicon of variables related to Agreeableness (especially, prosocial behavior vs. egotism) and to the inclusion of variables related to Intellect. Tellegen's Big Three tends to be based on a narrower variable selection, probably because their rationale for variable selection puts a greater emphasis on subjective affect and on psychopathology than is found in lexicons.

\section{Analyses Involving Imposed-Etic Structures}

Ratings on the markers for each scale (see Appendix) were summed into a single score, representing one particular factor within a structure. These factor-scale scores were then correlated 
with factor scores derived from the corresponding emic-structure solution of one, two, five, six, seven, or eight factors. These correlations allowed us to compare the degree of replication of the various imposed-etic structures in Greek data.

\section{Results}

\section{Effects of Variable Selection}

We first examined the effects of variable selection on the factor structures, using factors generated from all three samples. Table 1 presents, for factor structures varying by number of factors and by use of original versus ipsatized data, the correlations between pairs of best-match factors from the 400 most frequent descriptors and the reduced set of 248. Table 2 presents similar correlations comparing structures from the 400 highest clarity descriptors and the 248 .

Coefficients in these tables indicate that, for the original data, structures of one, two, three, and six factors were fairly invariant across variable selections. For ipsatized data, structures of one, two, four, and five factors were fairly invariant across variable selections. One can see that one- and two-factor structures were invariant across variable selections, regardless of whether original or ipsatized data were used. Structures of seven or more factors always led to at least one relatively poor match $(r<.80)$ between some pair of best-matched factors. Although this finding does not dictate that solutions of seven factors or more should be removed from consideration, it does suggest that we should exercise some caution regarding such solutions because of their higher degree of dependence on variable selection. The finding of some variableselection effects gives even more reason to concentrate on the
400-HFD (and thus Sample 1) in subsequent analyses. We stress, however, that to the extent that we concentrate on structures with one, two, or six factors (as we do), these variable selection effects are minimal.

\section{Within-Language Replicability (Emic Analyses)}

To examine within-language replicability, we randomly divided Sample 1 in half (i.e., 495 in one subsample, 496 in the other) and examined whether the principal components generated in one half, for each number of factors, had high matching congruence coefficients with those from the other half. A table presenting the best-match congruencies for 1 to 10 factors in the original data and in ipsatized data is available from Gerard Saucier, but these results are summarized here.

For 1 to 10 factors, in order, in original data the mean bestmatch congruencies were $.98, .97, .96, .94, .91, .86, .84, .85, .78$, and .77 , whereas those for ipsatized data were $.94, .97, .78, .80$, $.91, .77, .74, .74, .68$, and .68. For solutions of 1 to 4 factors in the original data, and one and two factors in the ipsatized data, all congruence coefficients were above the conventional threshold of .90. These solutions can be considered highly robust across subsamples. Thus, one- and two-factor solutions were stable and robust not only across variable selections but also across subsamples, as was true in an earlier study of English adjectives (Saucier, 1997).

Figure 1 depicts (for original data) the pattern of factor emergence as successively more factors are extracted and rotated. Figure 2 provides the analogous pattern of factor emergence for ipsatized-data factors. We next offer a few comments on the

Table 1

Best-Match Correlations Between 248-HCFD and 400-HFD Factors

\begin{tabular}{|c|c|c|c|c|c|c|c|c|c|c|c|}
\hline \multirow[b]{2}{*}{ No. of factors } & \multicolumn{10}{|c|}{ Correlations in Rank Order } & \multirow[b]{2}{*}{$M$} \\
\hline & $1 \mathrm{st}$ & 2nd & $3 r d$ & 4th & 5 th & 6th & 7 th & 8 th & 9th & 10th & \\
\hline \multicolumn{12}{|l|}{ Original data } \\
\hline 1. & .99 & & & & & & & & & & $.99^{\mathrm{a}}$ \\
\hline 2. & .98 & .97 & & & & & & & & & $.98^{\mathrm{a}}$ \\
\hline 3. & .93 & .91 & .84 & & & & & & & & .89 \\
\hline 4. & .96 & .94 & .93 & .88 & & & & & & & $.93^{\mathrm{a}}$ \\
\hline 5. & .96 & .93 & .93 & .93 & .84 & & & & & & $.92^{\mathrm{a}}$ \\
\hline 6. & .98 & .97 & .96 & .95 & .94 & .90 & & & & & $.95^{\mathrm{a}}$ \\
\hline 7. & .96 & .94 & .93 & .92 & .89 & .86 & .44 & & & & .85 \\
\hline 8. & .97 & .96 & .96 & .96 & .95 & .78 & .77 & .55 & & & .86 \\
\hline 9. & .96 & .95 & .95 & .86 & .84 & .79 & .73 & .62 & .49 & & .80 \\
\hline 10. & .97 & .94 & .93 & .91 & .89 & .87 & .78 & .75 & .60 & .55 & .82 \\
\hline \multicolumn{12}{|l|}{ Ipsatized data } \\
\hline 1. & .98 & & & & & & & & & & $.98^{\mathrm{a}}$ \\
\hline 2. & .99 & .98 & & & & & & & & & $.98^{\mathrm{a}}$ \\
\hline 3. & .92 & .85 & .38 & & & & & & & & .72 \\
\hline 4. & .98 & .98 & .96 & .96 & & & & & & & $.97^{\mathrm{a}}$ \\
\hline 5. & .96 & .96 & .94 & .93 & .92 & & & & & & $.94^{\mathrm{a}}$ \\
\hline 6. & .96 & .93 & .93 & .80 & .76 & .40 & & & & & .76 \\
\hline 7. & .94 & .90 & .79 & .69 & .65 & .49 & .47 & & & & .70 \\
\hline 8. & .95 & .95 & .94 & .79 & .77 & .70 & .59 & .55 & & & .78 \\
\hline 9. & .94 & .88 & .80 & .72 & .63 & .61 & .38 & .38 & .27 & & .62 \\
\hline 10. & .95 & .82 & .82 & .79 & .75 & .66 & .63 & .62 & .42 & .16 & .66 \\
\hline
\end{tabular}

Note. $\quad N=991 . \mathrm{HCFD}=$ high clarity and frequency descriptors; HFD $=$ high frequency descriptors.

${ }^{a}$ Indicates mean correlation of .90 or greater. 
Table 2

Best-Match Correlations Between 248-HCFD and 400-HCD Factors

\begin{tabular}{|c|c|c|c|c|c|c|c|c|c|c|c|}
\hline \multirow[b]{2}{*}{ No. of factors } & \multicolumn{10}{|c|}{ Correlations in Rank Order } & \multirow[b]{2}{*}{$M$} \\
\hline & $1 \mathrm{st}$ & 2nd & $3 \mathrm{rd}$ & 4th & 5 th & 6 th & 7 th & 8th & 9th & 10th & \\
\hline \multicolumn{12}{|l|}{ Original data } \\
\hline 1. & .98 & & & & & & & & & & $.98^{\mathrm{a}}$ \\
\hline 2. & .97 & .96 & & & & & & & & & $.96^{\mathrm{a}}$ \\
\hline 3. & .96 & .94 & .93 & & & & & & & & $.94^{\mathrm{a}}$ \\
\hline 4. & .91 & .91 & .85 & .70 & & & & & & & .84 \\
\hline 5. & .92 & .89 & .86 & .83 & .72 & & & & & & .84 \\
\hline 6. & .95 & .94 & .94 & .93 & .93 & .93 & & & & & $.94^{\mathrm{a}}$ \\
\hline 7. & .93 & .93 & .93 & .92 & .89 & .84 & .41 & & & & .84 \\
\hline 8. & .95 & .93 & .93 & .91 & .85 & .84 & .60 & .51 & & & .81 \\
\hline 9. & .95 & .93 & .93 & .93 & .89 & .85 & .81 & .76 & .73 & & .86 \\
\hline 10. & .94 & .94 & .94 & .92 & .89 & .88 & .84 & .80 & .78 & .76 & .87 \\
\hline \multicolumn{12}{|l|}{ Ipsatized data } \\
\hline 1. & .97 & & & & & & & & & & $.97^{\mathrm{a}}$ \\
\hline 2. & .97 & .96 & & & & & & & & & $.98^{\mathrm{a}}$ \\
\hline 3. & .96 & .95 & .95 & & & & & & & & $.95^{\mathrm{a}}$ \\
\hline 4. & .94 & .93 & .93 & .89 & & & & & & & $.92^{\mathrm{a}}$ \\
\hline 5. & .95 & .93 & .93 & .92 & .92 & & & & & & $.93^{\mathrm{a}}$ \\
\hline 6. & .95 & .94 & .92 & .90 & .88 & .34 & & & & & .82 \\
\hline 7. & .92 & .92 & .91 & .86 & .82 & .62 & .42 & & & & .78 \\
\hline 8. & .93 & .89 & .85 & .80 & .80 & .75 & .73 & .42 & & & .77 \\
\hline 9. & .94 & .83 & .82 & .81 & .80 & .71 & .70 & .62 & .53 & & .75 \\
\hline 10. & .94 & .84 & .84 & .80 & .75 & .71 & .64 & .57 & .55 & .37 & .70 \\
\hline
\end{tabular}

Note. $\quad N=429$. HCFD $=$ high clarity and frequency descriptors; $\mathrm{HCD}=$ high clarity descriptors .

${ }^{\text {a }}$ Indicates mean correlation of .90 or greater.

overall pattern of factor emergence, with attention to the structures that we have identified as being particularly robust across variable selections and across subsamples.

The first unrotated factor corresponds to Evaluation; highloading terms (in English translation) include sympathetic, likable, cute, and capable versus lazy, incorrigible, annoying, and unstable. The two-factor structure consists of one factor emphasizing Morality and Social Propriety (including high-loading terms humble, industrious, considerate, and responsible versus badtempered, gross, disrespectful, and ironic) and another factor emphasizing Dynamism (including high-loading terms dynamic, exciting, energetic, and irresistible versus gutless, coward, hesitant, and boring). At the three-factor level, a Sensitivity factor is added. At the four-factor level, Dynamism breaks in two, with one factor representing positive affect and the other factor emphasizing competence (e.g., high-loading terms successful, talented) and courage. At the five-factor level, Sensitivity shifts into an Introversion/Melancholia factor, and the broader Morality factor splits into one factor of Even Temper and another combining Negative Valence and Honesty. At the six-factor level, a Conscientiousness factor is added. Beginning with the seven-factor solutions, there was always at least one low-saturation factor with very heterogeneous content that was difficult to label and interpret; it is at this level that variable-selection effects became more pronounced, so these emic solutions are not considered further.

Accordingly, we emphasize the six-factor solution, the highest loading terms from which are presented in Table 3. Inspection of the five-factor solution in ipsatized data indicated great similarity to this six-factor (original data) solution; the substantial difference was that two original-data factors (Agreeableness/Positive Affect and Introversion/Melancholia) were combined into a single ipsatized-data factor, which counterposes Positive Affect/Sociability at one pole with Introversion/Melancholia at the other.

Table 3 also presents loadings for each term in the two-factor solution. The table does not, however, necessarily include all of the highest loading terms for the two-factor solution: For the Morality/ Social-Propriety factor, the terms were unreasonable, badtempered, unbalanced, incorrigible, and ironic on one pole with responsible, hardworking, considerate, industrious, and consistent on the other; for Dynamism, they were dynamic, cute, adorable, exciting, and alive on one pole, with gutless, boring, antisocial, cowardly, and opinionless on the other.

\section{Between-Language Replicability (Etic Analyses)}

Table 4 presents correlations among all the marker scales. Within marker sets, scale intercorrelations were never higher than .37 in magnitude, another indication (along with their coefficient alpha reliability estimates provided in the Appendix) that these scales were useful.

Table 5 provides the correlations between the best-match pairs of imported marker scales and the Greek-emic factors. For evaluating replicability, a key proportion is the signal:noise ratio discernible by comparing the mean convergent correlation with the mean divergent correlation. If replication is strong, this proportion (regardless of the level of internal consistency in the marker scales) will be high, whereas if weak, this proportion will be low. As an aid in discerning the relation of signal to noise, we provide Figure 3, which graphs the levels of convergence ascending on the 
Original Data

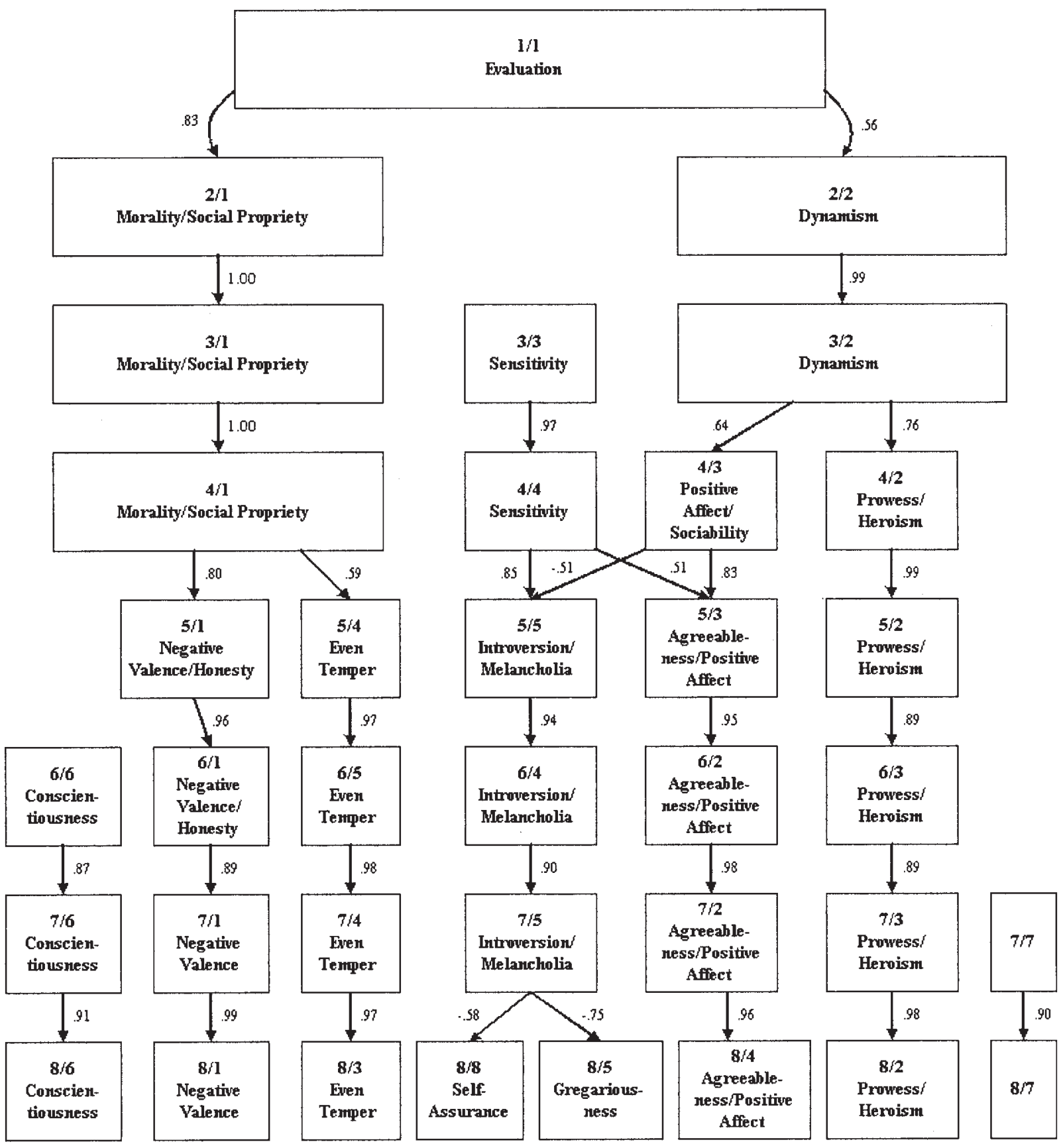

Figure 1. Pattern of factor emergence for original data.

vertical axis and the levels of divergence descending on the horizontal axis. In Figure 3, the absolute ideal (unattainable given the imprecision of real-world measurement) would be found in the extreme upper right corner; the closer a model approaches this part of the graph, the clearer the replication. Because the one-factor model has no divergent correlations, it could not be included in
Figure 3; however, Table 4 suggests that the one-factor models had a level of replication comparable to that of the Big Two.

It is clear that these broad-factor models replicate in these data to a far greater degree than they do in the models with a larger number of factors. For the Big Two, the mean convergent correlations are substantially higher than for all other models, while at 


\section{Ipsatized Data}

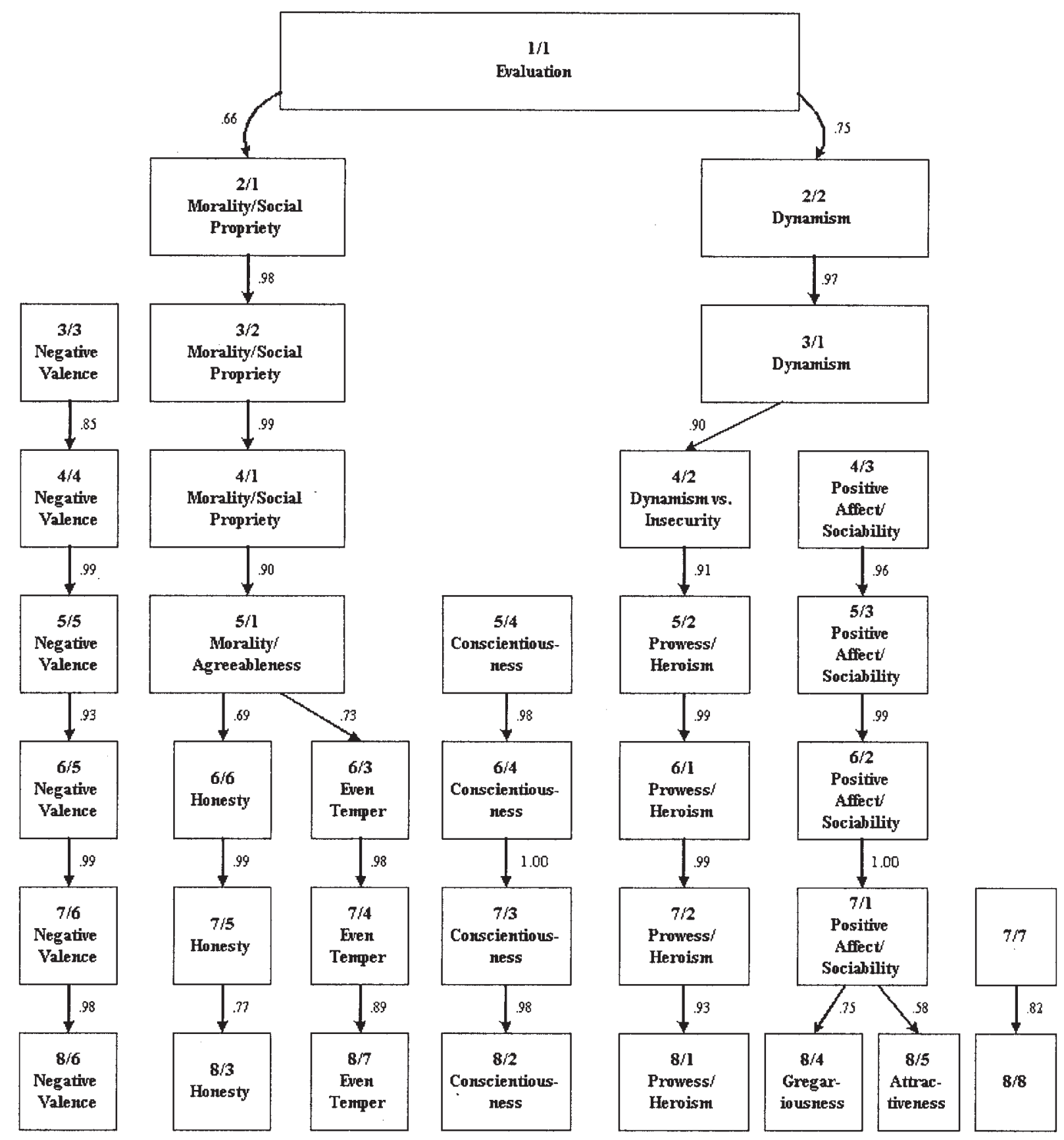

Figure 2. Pattern of factor emergence for ipsatized data.

the same time the mean divergent correlations are all lower. As a result, in Figure 3, the Big Two stands above the crowd formed by the other models. This superior replication was evident in ipsatized as well as original data.

It is difficult to differentiate within the crowd of data points in the lower left of Figure 3, except to say that the Big Three had a noticeably lower level of replication than any of the five-, six-, or seven-factor models. It is difficult to draw strong contrasts between the replicabilities of various five- to seven-factor models in these data; in a competition to achieve the best cross-cultural replicability, they appear virtually "tied" in this Greek-language study.

Table 4 and Figure 3 also include one variant of the Big Five-Big Five plus Negative Valence-that was added post hoc 
because there was little tendency toward formation of an Attractiveness factor in Greek lexical structures. This variant was modestly replicated to about the same degree as that achieved by the ML7. This post hoc model should be interpreted with some caution because it is proposed for the first time here and may reflect idiosyncrasies in these data.

The modest replication of all of these models with five to seven factors can be traced principally to two causes. First, each of these a priori models contains some variant of an Intellect/Imagination/ Openness factor. However, in the emic structures Intellect content remained combined with Self-Assurance content in the "Prowess/ Heroism" factor displayed in Figure 1. Second, in the emic structures, Agreeableness and Positive Affect combine in a single factor, which has not been previously observed in a lexical study.

The relatively poor showing of the Big Five in the etic analysis stimulated us to examine the results when a Big-Five structure was forced on the data, via target rotation, as a post hoc analysis. We used the target rotation option from the CEFA (Comprehensive Exploratory Factor Analysis) program (Browne, Cudeck, Tateneni, \& Mels, 2002), which allows partially unspecified loadings for variables. Each of the set of markers for each Big-Five scale (see Appendix) was targeted to load 1.00 (or -1.00 for reverse-keyed items) on one of the factors and .00 on the other four. Thus, loadings were specified for only those 35 variables that were part of marker scales, with the other 365 variables having all their loadings unspecified. This target rotation produced five orthogonal factors that accounted for as much variance as the first five unrotated factors. However, it did not yield a complete Big Five. For the Intellect factor, none of the marker items had its highest loading on the targeted factor, and marker-item loadings on that factor were small, ranging from .14 to .20 , indicating the near impossibility of finding an orthogonal Intellect factor in these data. For the other four factors, about one fourth of the marker items had their highest loading on a nontargeted factor, but overall over one third of the marker items did so.

As a comparison, we executed the same procedure with two factors. We used the Big Two marker scales (see Appendix) and specified loadings ( 1 or -1 , or 0 ) for these 18 variables, while leaving loadings for the other 382 unspecified. In this target rotation, all of the $\mathrm{S}$ markers and seven of the nine D markers loaded most highly on the expected factor (in total, only one ninth of the marker items failing to do so). The findings using targeted rotation, whether for the Big Five or the Big Two, are consistent with the replication coefficients in Table 5 .

One might argue that the appearance of a Negative Valence factor in the Greek structures distorts the replication comparisons above. If this distortion is occurring, then after discounting the Negative Valence factor in the solutions, the Big Five might be well replicated in the six-factor solutions or the six-factor model might be well replicated in the seven-factor solutions.

Discounting the Negative Valence factor, Big-Five markers correlated $.58, .64, .59, .58$, and .59 (for Extraversion through Intellect, in the same order as in Table 4) with Factors 2 through 6 in the original data, and they correlated $.55, .44, .72, .67$, and .10 with Factors 1 through 4 and 6 in the ipsatized data. The mean convergent, best-match correlations, then, were .60 for original data and .49 for ipsatized data compared with mean divergent correlations of .19 for original data and .18 for ipsatized data. Compared with the Big-Five replication coefficients in Table 5, we see that the procedure of discounting Negative Valence slightly improved the average convergent correlation $(+.04)$ in the original data and very slight worsened it $(-.02)$ in ipsatized data.

Discounting the Negative Valence factor, the six-factor markers correlated .70, .42, .71,.64, .60, and .44 (for Extraversion through Honesty, in the same order as in Table 4) with Factors 2 through 7 in the original data and correlated $.63, .78, .73, .71, .15$, and .57 with Factors 1 through 5 and 7 in the ipsatized data. The mean convergent, best-match correlations, then, were .58 for the original data and .59 for the ipsatized data compared with mean divergent correlations of .16 for the original data and .14 for ipsatized data. Compared with the six-factor model replication coefficients in Table 5, the procedure of discounting Negative Valence led to no improvement in the average convergent correlation in the original data and a very slight worsening $(-.02)$ in ipsatized data.

The appearance of a Negative Valence factor, then, does not appear to distort the replication comparisons. Another approach to removing the effects of a Negative Valence factor is to remove terms that have unusually low endorsement means because such terms tend preponderantly to contribute to such a factor. However, in this Greek variable selection, such an approach would discard too much: The 10 terms with lowest endorsement include the commonly accepted descriptors dishonest, merciless, unpleasant, and uneducated, and the 25 lowest also include the commonly accepted descriptors sly, petty, incapable, and unsympathetic.

Overall, then, there are two main findings from the etic analysis. First, one- and two-factor models of personality structure are better replicated among Greek personality descriptors than are any competitor models (i.e., the Big Five or others). This is consistent with previous studies (summarized by Saucier \& Goldberg, 2001) in which these broad structures have consistently replicated in analyses from lexical studies. Additionally, given the relation of these factors to the classic Osgood "affective meaning" factors-long demonstrated to have a high degree of cross-cultural ubiquitythis finding is not surprising. Saucier (2003b) similarly found a superior replication of one- and two-factor models in a recent study of English-language personality type nouns.

It is difficult to distinguish among the five-, six-, and sevenfactor models we tested with respect to their replication in Greek. One of these models may eventually turn out to have superior cross-language replicability, but the results in Greek are not decisive toward that result.

\section{Discussion}

\section{Are There Cross-Culturally Generalizable Personality Factors?}

Recent lexical studies have focused on evaluating the replicability of structures with five to seven factors. Correspondence of Greek structures with these imported models was only moderate, apparently limited especially by the Greek structures' tendency to fuse Intellect and Self-Assurance/Extraversion content into a single Prowess/Heroism factor. The fusion of these kinds of content into a single factor was not anticipated in any of the imposed models and may even be a culture-specific pattern in the Greek personality lexicon. Overall, then, the present results are not very 
Table 3

Highest-Loading Terms on Six Emic Greek Factors

\begin{tabular}{|c|c|c|c|c|c|c|c|c|}
\hline \multirow[b]{2}{*}{ Translated term } & \multicolumn{6}{|c|}{ Six-factor solution } & \multicolumn{2}{|c|}{$\begin{array}{l}\text { Two-factor } \\
\text { solution }\end{array}$} \\
\hline & $\mathrm{NV} / \mathrm{H}$ & $\mathrm{A} / \mathrm{PA}$ & $\mathrm{P} / \mathrm{H}$ & $\mathrm{I} / \mathrm{M}$ & ET & $\mathrm{C}$ & S & $\mathrm{D}$ \\
\hline Barbarous & .65 & -.12 & .06 & .03 & .07 & .04 & .56 & -.09 \\
\hline Corrupt & .64 & -.09 & .05 & .00 & .03 & .11 & .54 & -.08 \\
\hline Inhuman & .60 & -.14 & .02 & -.04 & .01 & .00 & .46 & -.11 \\
\hline Abject & .60 & -.14 & -.03 & .11 & -.09 & .09 & .46 & -.22 \\
\hline Perverse & .59 & -.04 & .08 & .00 & .10 & .13 & .54 & -.01 \\
\hline Immodest & .58 & -.05 & -.04 & -.05 & .11 & .11 & .52 & -.08 \\
\hline Disgusting & .57 & -.11 & -.04 & .09 & -.03 & .15 & .48 & -.19 \\
\hline Dishonorable & .57 & -.09 & -.05 & -.01 & .01 & .03 & .44 & -.13 \\
\hline Unpleasant & .56 & -.07 & -.07 & .10 & -.10 & .06 & .41 & -.19 \\
\hline Intrigueful & .56 & .08 & .03 & -.04 & .17 & -.07 & .49 & .08 \\
\hline Calumniator & .56 & .02 & -.02 & .02 & .13 & .01 & .50 & -.03 \\
\hline Immoral & .54 & -.07 & .01 & -.04 & .15 & .13 & .52 & -.05 \\
\hline Dishonest & .54 & -.07 & .00 & .01 & .06 & .04 & .46 & -.08 \\
\hline Unacceptable & .54 & -.08 & -.07 & .12 & .02 & .18 & .49 & -.19 \\
\hline Merciless & .53 & -.19 & .03 & -.01 & .04 & -.03 & .42 & -.13 \\
\hline Pathetic & .53 & -.02 & -.13 & .23 & -.06 & .05 & .42 & -.22 \\
\hline Vulgar & .53 & -.07 & .05 & -.01 & .14 & .17 & .46 & -.13 \\
\hline Gross & .53 & .04 & .04 & -.07 & .21 & .14 & .54 & .06 \\
\hline Cunning & .52 & -.05 & .11 & -.01 & .18 & .00 & .50 & .04 \\
\hline Cold & .51 & -.11 & .08 & .07 & .10 & .01 & .47 & -.06 \\
\hline Paranoid & .51 & -.04 & .05 & .11 & .14 & .19 & .55 & -.05 \\
\hline Useless & .51 & -.12 & -.13 & .21 & -.06 & .17 & .43 & -.29 \\
\hline Violent & .50 & -.11 & .12 & .05 & .22 & .06 & .55 & -.01 \\
\hline Loser & .50 & -.12 & -.05 & .12 & -.11 & -.09 & .37 & -.22 \\
\hline Stupid & .50 & -.07 & -.06 & .13 & .05 & .18 & .48 & -.17 \\
\hline Kind & -.20 & .62 & .13 & .06 & -.09 & -.09 & -.23 & .48 \\
\hline Warm & -.17 & .61 & .07 & -.09 & .01 & -.07 & -.18 & .49 \\
\hline Friendly & -.12 & .60 & .10 & -.14 & -.06 & .00 & -.16 & .50 \\
\hline Big-hearted & -.10 & .60 & .16 & .05 & -.08 & -.02 & -.12 & .48 \\
\hline Kind-hearted & -.21 & .60 & .14 & .12 & -.08 & .00 & -.19 & .45 \\
\hline Cute & -.04 & .60 & .20 & -.20 & .03 & -.14 & -.10 & .60 \\
\hline Good-natured & -.16 & .58 & .07 & .09 & -.13 & -.13 & -.23 & .40 \\
\hline Open-hearted & -.09 & .58 & .05 & -.19 & -.01 & .03 & -.12 & .47 \\
\hline Lovable & -.05 & .58 & .13 & -.19 & .00 & -.15 & -.13 & .53 \\
\hline Sweet & -.05 & .57 & .17 & -.08 & -.06 & -.15 & -.14 & .52 \\
\hline Big-hearted & -.13 & .56 & .13 & .05 & -.07 & -.13 & -.17 & .46 \\
\hline Amusing & .00 & .55 & .07 & -.31 & .15 & .06 & .01 & .51 \\
\hline Affectionate & -.26 & .55 & .13 & .13 & .01 & .01 & -.17 & .43 \\
\hline Smiling & -.12 & .55 & .10 & .25 & -.03 & .10 & -.14 & .49 \\
\hline Tender & -.09 & .54 & .03 & .00 & .05 & -.05 & -.07 & .39 \\
\hline Likable & -.14 & .54 & .16 & -.16 & -.04 & -.13 & -.20 & .52 \\
\hline Cheerful & -.03 & .53 & .08 & -.38 & -.09 & .01 & -.16 & .49 \\
\hline Adorable & .03 & .53 & .25 & -.22 & -.03 & -.21 & -.09 & .59 \\
\hline Cheerful & -.03 & .53 & .20 & -.17 & .02 & .17 & .00 & .52 \\
\hline Sympathetic & -.13 & .53 & .18 & -.18 & -.06 & -.13 & -.21 & .53 \\
\hline Cordial & -.18 & .52 & .19 & -.03 & -.06 & .09 & -.15 & .47 \\
\hline Pleasant & .00 & .52 & .14 & -.30 & .05 & -.06 & -.06 & .53 \\
\hline Accommodating & -.18 & .52 & .16 & .10 & -.13 & -.11 & -.23 & .42 \\
\hline Demonstrative & -.11 & .51 & .08 & -.20 & .19 & .11 & .00 & .48 \\
\hline Hospitable & -.26 & .51 & .09 & .01 & -.11 & .01 & -.26 & .39 \\
\hline Unselfish & -.13 & .51 & .26 & .03 & -.07 & -.02 & -.13 & .50 \\
\hline Human & -.31 & .50 & .14 & .08 & -.06 & -.04 & -.27 & .41 \\
\hline Inventive & .05 & .08 & .62 & .00 & -.01 & .10 & .12 & .45 \\
\hline Multitalented & .14 & .18 & .56 & -.08 & -.01 & .01 & .14 & .50 \\
\hline Talented & .15 & .20 & .56 & -.11 & -.06 & -.06 & .09 & .52 \\
\hline Ingenious & .08 & .07 & .56 & -.13 & -.01 & .03 & .10 & .44 \\
\hline Fighter & -.03 & .07 & .55 & -.11 & .12 & -.04 & .07 & .47 \\
\hline Pioneering & .14 & .11 & .54 & -.17 & .08 & .01 & .17 & .48 \\
\hline Genius & .21 & .16 & .54 & -.11 & -.01 & -.02 & .18 & .48 \\
\hline Inventive & .02 & .13 & .54 & .00 & .02 & .19 & .13 & .43 \\
\hline Autonomous & -.09 & -.07 & .53 & -.07 & -.03 & .09 & -.01 & .32 \\
\hline Genius & .16 & .06 & .53 & -.04 & .02 & .01 & .18 & .39 \\
\hline Dynamic & -.09 & .21 & .53 & -.29 & .15 & -.16 & -.05 & .62 \\
\hline
\end{tabular}


Table 3 (continued)

\begin{tabular}{|c|c|c|c|c|c|c|c|c|}
\hline \multirow[b]{2}{*}{ Translated term } & \multicolumn{6}{|c|}{ Six-factor solution } & \multicolumn{2}{|c|}{$\begin{array}{l}\text { Two-factor } \\
\text { solution }\end{array}$} \\
\hline & $\mathrm{NV} / \mathrm{H}$ & $\mathrm{A} / \mathrm{PA}$ & $\mathrm{P} / \mathrm{H}$ & $\mathrm{I} / \mathrm{M}$ & ET & $\mathrm{C}$ & $\mathrm{S}$ & $\mathrm{D}$ \\
\hline Agonistic & -.04 & .10 & .52 & -.09 & .11 & -.13 & .03 & .48 \\
\hline Successful & -.03 & .19 & .51 & -.20 & -.04 & -.15 & -.08 & .53 \\
\hline Sad & .16 & -.10 & -.12 & .59 & .17 & .02 & .33 & -.29 \\
\hline Depressive & .17 & -.03 & -.12 & .57 & .27 & .05 & .40 & -.23 \\
\hline Insecure & .06 & .08 & -.20 & .56 & .18 & .22 & .30 & -.23 \\
\hline Hesitant & .11 & .01 & -.25 & .54 & .08 & .20 & .27 & -.32 \\
\hline Melancholic & .09 & .01 & -.18 & .54 & .26 & .02 & .31 & -.22 \\
\hline Pessimistic & .05 & -.03 & -.27 & .50 & .24 & .03 & .25 & -.30 \\
\hline Moody & .24 & -.19 & -.09 & .50 & .23 & .02 & .41 & -.30 \\
\hline Loner & .09 & -.20 & .04 & .50 & .09 & -.02 & .23 & -.23 \\
\hline Taciturn & .12 & -.23 & .00 & .49 & -.08 & -.13 & .12 & -.30 \\
\hline Cowardly & .09 & .00 & -.29 & .49 & .03 & .12 & .19 & -.35 \\
\hline Touchy & .18 & -.02 & -.01 & .16 & .61 & .07 & .52 & .03 \\
\hline Aggressive & .23 & -.04 & .06 & .02 & .59 & .03 & .51 & .10 \\
\hline Nervous & .04 & .04 & -.06 & .06 & .58 & -.02 & .34 & .07 \\
\hline Touchy & .07 & .04 & -.01 & .15 & .56 & .04 & .39 & .07 \\
\hline Reactive & .17 & .01 & .08 & .07 & .55 & .10 & .48 & .12 \\
\hline Abrupt & .22 & -.09 & .05 & .13 & .55 & .11 & .53 & .02 \\
\hline Fretful & .13 & .07 & -.11 & .26 & .54 & .08 & .45 & -.02 \\
\hline Neurotic & .25 & .02 & -.11 & .28 & .52 & .02 & .52 & -.07 \\
\hline Impatient & .05 & .22 & -.04 & .13 & .52 & .17 & .38 & .15 \\
\hline Brawling & .30 & .05 & -.04 & -.04 & .52 & .05 & .50 & .08 \\
\hline Calm & .00 & .09 & .11 & .06 & -.52 & -.03 & -.27 & .02 \\
\hline Disorganized & .24 & -.08 & -.10 & .13 & .08 & .53 & .40 & -.21 \\
\hline Untidy & .19 & -.08 & .02 & .12 & .16 & .53 & .41 & -.11 \\
\hline Neglectful & .30 & -.10 & -.05 & .18 & .07 & .48 & .44 & -.20 \\
\hline Unscheduled & .25 & .00 & -.08 & .16 & .12 & .48 & .42 & -.14 \\
\hline Lazy & .27 & -.09 & -.11 & .10 & .20 & .47 & .46 & -.19 \\
\hline Carefree & .13 & .22 & .11 & -.08 & -.03 & .47 & .21 & .18 \\
\hline Inconsistent & .36 & -.07 & -.11 & .07 & .09 & .46 & .46 & -.19 \\
\hline Absentminded & .17 & .00 & -.11 & .27 & .23 & .46 & .42 & -.16 \\
\hline Organized & -.06 & .14 & .30 & .04 & -.03 & -.48 & -.16 & .32 \\
\hline Hardworking & -.24 & .18 & .22 & .01 & -.05 & -.45 & -.32 & .32 \\
\hline
\end{tabular}

Note. $\quad N=991$. In cases in which an English word is repeated, two Greek words best translated into the same English word. The 10 highest magnitude loadings for each of the six factors are shown, and any further terms with any loadings over .50 are also shown. Loadings over .50 are in boldface type. $\mathrm{NV} / \mathrm{H}=$ Negative Valence/Honesty; A/PA = Agreeableness/Positive Affect; $\mathrm{P} / \mathrm{H}=$ Prowess/Heroism; $/ \mathrm{M}=$ Introversion/ Melancholia; ET = Even Temper; $\mathrm{C}=$ Conscientiousness; $\mathrm{S}=$ Social Propriety (loadings reflected); $\mathrm{D}=$ Dynamism.

supportive of the cross-cultural generalizability of structures at the five- to seven-factor level.

Yet at the very broadest levels, the emic structure of Greek personality descriptors does not appear to be much different from that found in other languages. One-factor solutions produce an Evaluation factor, and two factor solutions produce Morality (Social Propriety) and Dynamism factors. These factors do seem to have a high degree of cross-cultural generalizability.

The present results shed some light on which aspects of personality structure are universal and which are not. It may be that, as Osgood's work indicated, humans universally divide attributes according to their relevance to Morality and Dynamism categories. Humans may universally tend to categorize and differentiate persons, including themselves, according to whether the person is benign versus harmful and stimulating versus boring. There are indications that these categories are widely shared schemas; Saucier and Simonds (2005) have found that this structure replicates well at the individual level, whereas the Big Five does not. We suggest that the ubiquity of these person perception categories may be related to the operation of two hypothesized brain systems (Gray, 1986). The human behavioral inhibition system is concerned with threat and danger, and the operation of this system tends to generate a benign versus harmful dimension in perception of other persons. The human behavioral activation system is concerned with stimulation and reward, and the operation of this system tends to generate a dynamic-stimulating versus boring dimension in perception of other persons.

These two categories can be further subdivided, making finer distinctions, and the Big Five is one example of such finer distinctions. The particular distinctions used in person perception schemas may, however, vary a good deal from one person to another, as well as from one culture to another and from one language to another. There has not been support, for example, for a view that the Big Five represent common ways in which information is represented or schematized in memory (Dabady, Bell, \& Kihlstrom, 1999). 
Table 4

Intercorrelations of Marker Scales

\begin{tabular}{|c|c|c|c|c|c|c|c|c|c|c|c|}
\hline Marker scales and factor codes & 1 & 2 & 3 & 4 & 5 & 6 & 7 & 8 & 9 & 10 & 11 \\
\hline \multicolumn{12}{|l|}{ 1. Evaluation (1sd.) } \\
\hline 2. Dynamism (2d.) & 35 & & & & & & & & & & \\
\hline 3. Social Propriety (2s.) & 70 & 09 & & & & & & & & & \\
\hline 4. Extraversion (5e.) & 20 & 66 & -01 & & & & & & & & \\
\hline 5. Agreeableness (5a.) & 57 & 36 & 57 & 20 & & & & & & & \\
\hline 6. Conscientiousness (5c.) & 55 & 12 & 35 & 15 & 24 & & & & & & \\
\hline 7. Emotional Stability (5es.) & 27 & 25 & 18 & 28 & 22 & 21 & & & & & \\
\hline 8. Intellect (5i.) & 06 & 20 & -08 & 20 & -06 & 05 & 18 & & & & \\
\hline 9. Attractiveness (5at.) & 37 & 56 & 28 & 34 & 40 & 23 & 25 & 07 & & & \\
\hline 10. Negative Valence $(5 \mathrm{nv})$. & -38 & -18 & -38 & -11 & -17 & -20 & -05 & -22 & -21 & & \\
\hline 11. Extraversion (6x.) & 32 & 70 & 07 & 81 & 27 & 16 & 27 & 16 & 38 & -17 & \\
\hline 12. Emotionality (6e.) & -03 & -28 & 15 & -37 & 09 & -08 & -65 & -28 & -13 & 04 & -33 \\
\hline 13. Agreeableness (6a.) & 48 & -09 & 60 & -18 & 39 & 20 & 35 & -10 & 16 & -09 & -13 \\
\hline 14. Conscientiousness (6c.) & 52 & 16 & 36 & 21 & 28 & 76 & 17 & 09 & 27 & -25 & 20 \\
\hline 15. Openness (6o.) & 05 & 31 & -13 & 33 & -06 & 05 & 27 & 56 & 18 & -16 & 31 \\
\hline 16. Honesty (6h.) & 39 & 00 & 46 & -07 & 32 & 23 & 08 & -01 & 08 & -29 & -03 \\
\hline 17. Gregariousness $(7 \mathrm{~g})$. & 18 & 70 & -04 & 64 & 23 & 00 & 17 & 12 & 33 & -08 & 73 \\
\hline 18. Self-Assurance (7s.) & 24 & 50 & 06 & 58 & 18 & 24 & 63 & 24 & 37 & -23 & 52 \\
\hline 19. Even-Temper (7e.) & 35 & 04 & 38 & 05 & 28 & 21 & 67 & 00 & 14 & 04 & 04 \\
\hline 20. Concern for Others ( $7 \mathrm{cf}$.) & 50 & 16 & 62 & 07 & 62 & 26 & 06 & -14 & 30 & -25 & 13 \\
\hline 21. Conscientiousness ( $7 \mathrm{co}$.) & 44 & 04 & 22 & 10 & 07 & 83 & 11 & 05 & 10 & -17 & 09 \\
\hline 22. Originality $(7 \mathrm{o})$. & 13 & 20 & 03 & 21 & 03 & 16 & 31 & 72 & 14 & -22 & 18 \\
\hline 23. Negative Valence (7nv.) & -39 & 07 & -39 & 09 & -16 & -24 & -05 & -03 & -07 & 41 & 05 \\
\hline 24. Positive Valence (7pv.) & 37 & 40 & 28 & 28 & 33 & 34 & 37 & 13 & 62 & -23 & 33 \\
\hline 25. Negative Valence (7nv2.) & -34 & -02 & -39 & 06 & -20 & -16 & 09 & -04 & -09 & 68 & -01 \\
\hline 26. Positive Emotionality (7pe.) & 17 & 64 & -04 & 66 & 22 & -01 & 15 & 07 & 29 & -07 & 72 \\
\hline 27. Negative Emotionality (7ne.) & -32 & -12 & -32 & -05 & -28 & -16 & -72 & -07 & -26 & 05 & -09 \\
\hline 28. Agreeability (7a.) & 19 & -12 & 32 & -23 & 32 & 05 & 06 & -19 & 07 & 11 & -18 \\
\hline 29. Conscientiousness ( $7 \mathrm{cns}$.) & 54 & 11 & 36 & 10 & 23 & 83 & 16 & -02 & 20 & -17 & 13 \\
\hline 30. Conventionality ( $7 \mathrm{cnv}$.) & 32 & -08 & 37 & -09 & 28 & 31 & 03 & -26 & 08 & -02 & -06 \\
\hline
\end{tabular}

Note. Intercorrelations over .40 are in bold font.

\section{What Makes Factor Structures Differ Between Languages?}

The determination of whether any personality factor structure is cross-culturally generalizable depends on whether one uses a lenient or a strict criterion. A lenient criterion is mere "imposability," met by demonstrations that a given factor structure can be found in translations of a factor-marker measure in conjunction with a Procrustes approach to factor analysis (as in McCrae \& Costa, 1997). A strict criterion demands "ubiquity" in exploratory factor analysis; this criterion is met by demonstrations that a given factor structure can be found in any language that uses a variable selection rooted in the lexicon of that language (rather than a translation of some imported measure). The results of our study indicate that, in the Greek language, the Big Five did not meet a strict criterion for cross-cultural generalizability, and competitor six- and seven-factor models did not fare much better. Instead, one must go to fewer-factor models to find strong support for such a claim.

What leads factor structures to differ from one language to another? One possibility is phylogenetic, that languages with common origins have similar structures. The Big Five has appeared more regularly in Germanic languages, which tends to support this phylogenetic view. However, the other language family with consistently demonstrated tendencies to yield the Big Five is Slavic. What Germanic and Slavic languages share, distinct from other members of the Indo-European family of languages, is a long geographical history in northern Europe. This suggests that another possible source of variation in factor structure is geographicaltwo languages that share a similar locale are likely to structure personality attributes in similar ways.

The Greek language is part of the Indo-European family, like Germanic and Slavic. However, features of the factor structure found in the present study resemble those found in geographically adjacent nations, in studies of Italian (Di Blas \& Forzi, 1998) and Turkish (Goldberg \& Somer, 2000). Specifically, in each of these Mediterranean-region languages, if one examines fourand five-factor structures (using ipsatized data), one finds a similar pattern: One factor emphasizes outgoing positive emotions, a second a contrast between peacefulness and combativeness, a third a contrast between fortitude and fear-insecurity, and a fourth is a recognizable Conscientiousness factor. If terms with very high evaluative content are represented, as in the Greek and Turkish studies, there is also a fifth Negative Valence factor. Greek and Italian are both Indo-European languages, although from different branches of that family; Turkish is an Altaic language. Therefore, commonalities of structure among these three languages might be better attributed to geographical and historical factors (e.g., having been linked for centuries in ancient times as part of the Roman Empire) than to purely linguistic ones.

Linguistic affinity and geography are but two possible bases on which factor structures might vary. Other possibilities are culture 


\begin{tabular}{llllllllllllllllllllll}
\hline 12 & 13 & 14 & 15 & 16 & 17 & 18 & 19 & 20 & 21 & 22 & 23 & 24 & 25 & 26 & 27 & 28 & 29 & 30 \\
\hline
\end{tabular}

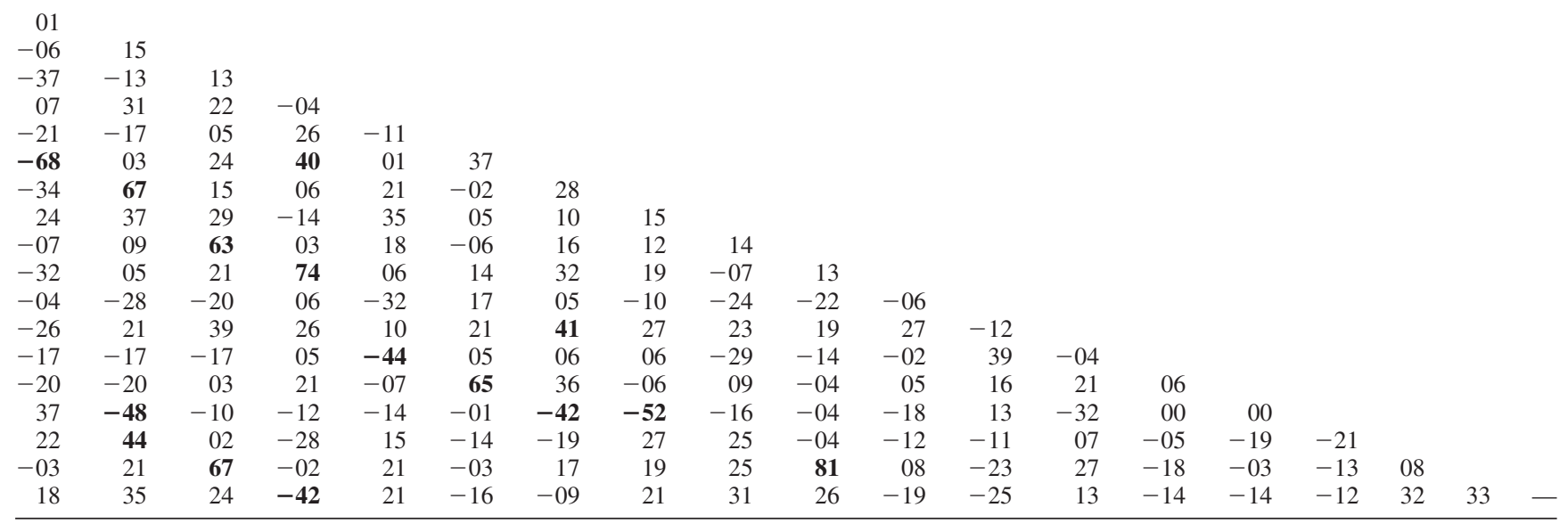

Table 5

Best-Match Correlations Between 400-HFD Factors and Imported Marker Scales

\begin{tabular}{|c|c|c|c|c|c|c|c|c|c|c|}
\hline \multirow[b]{2}{*}{ Imported model } & \multicolumn{8}{|c|}{ Best Match Correlations in Rank Order } & \multirow{2}{*}{$\begin{array}{c}\text { Convergent } \\
M\end{array}$} & \multirow{2}{*}{$\begin{array}{c}\text { Divergent } \\
M\end{array}$} \\
\hline & $1 \mathrm{st}$ & 2nd & $3 \mathrm{rd}$ & 4 th & 5 th & 6th & 7 th & 8 th & & \\
\hline \multicolumn{11}{|l|}{ Original Data } \\
\hline 1. Big One & .80 & & & & & & & & .80 & - \\
\hline 2. Big Two & .80 & .73 & & & & & & & .76 & .13 \\
\hline 3. Big Three & .64 & .48 & .32 & & & & & & .48 & .30 \\
\hline 4. Big Five & .63 & .61 & .56 & .54 & .44 & & & & .56 & .23 \\
\hline 5. Six Factors & .71 & .66 & .61 & .59 & .58 & .35 & & & .58 & .18 \\
\hline 6. Big Five $+N V$ & .79 & .68 & .64 & .59 & .59 & .58 & & & .63 & .18 \\
\hline 7. Big Five +2 & .77 & .67 & .66 & .64 & .61 & .59 & .27 & & .60 & .17 \\
\hline 8. Big Seven & .69 & .68 & .67 & .66 & .65 & .10 & .10 & & .51 & .16 \\
\hline 9. Multi-Language Seven (ML7) & .74 & .70 & .68 & .68 & .63 & .61 & .08 & & .59 & .14 \\
\hline 10. ML7 + Attractiveness & .78 & .72 & .70 & .69 & .65 & .63 & .50 & .23 & .61 & .14 \\
\hline \multicolumn{11}{|l|}{ Ipsatized data } \\
\hline 1. Big One & .74 & & & & & & & & .74 & - \\
\hline 2. Big Two & .80 & .73 & & & & & & & .77 & .12 \\
\hline 3. Big Three & .67 & .45 & .28 & & & & & & .47 & .27 \\
\hline 4. Big Five & .67 & .66 & .48 & .45 & .27 & & & & .51 & .18 \\
\hline 5. Six Factors & .79 & .74 & .70 & .64 & .57 & .20 & & & .61 & .13 \\
\hline 6. Big Five $+\mathrm{NV}$ & .72 & .68 & .67 & .55 & .44 & .10 & & & .52 & .17 \\
\hline 7. Big Five +2 & .72 & .66 & .65 & .60 & .42 & .15 & .11 & & .48 & .17 \\
\hline 8. Big Seven & .74 & .62 & .59 & .53 & .41 & .17 & .16 & & .46 & .16 \\
\hline 9. ML7 & .71 & .70 & .62 & .57 & .42 & .32 & .22 & & .51 & .16 \\
\hline 10. ML7 + Attractiveness & .75 & .71 & .70 & .69 & .51 & .51 & .43 & .10 & .55 & .15 \\
\hline
\end{tabular}

Note. $\mathrm{HFD}=$ high frequency descriptors; $\mathrm{NV}=$ Negative Valence. 


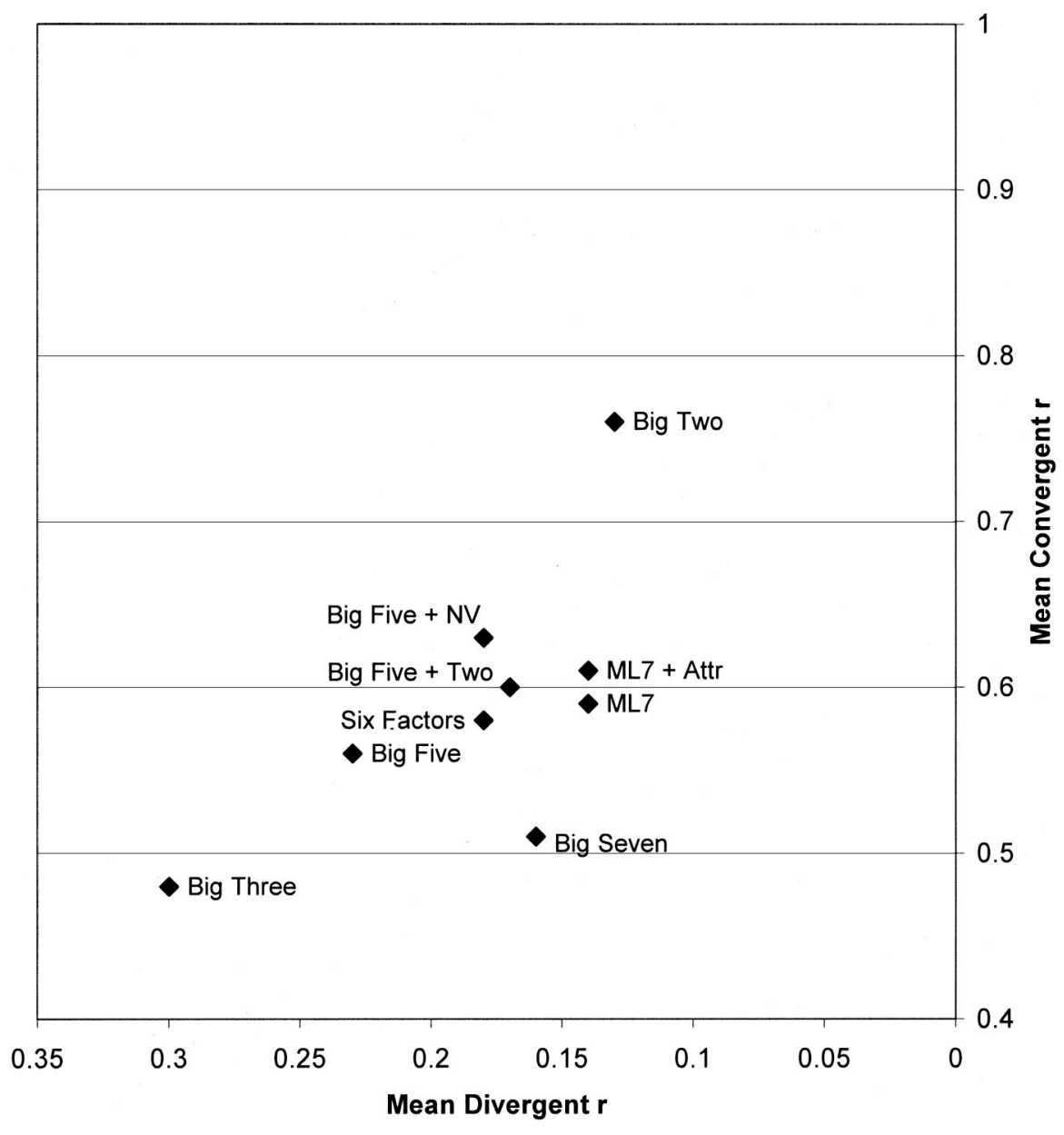

Figure 3. Degree of convergent and divergent replication for etic structural models. NV = Negative Valence; ML7 = Multi-Language Seven; Attr $=$ Attractiveness.

or predominant religion, or aspects of methodology like variable selection. Future studies can usefully address whether linguistic affinity, geography, culture, religion, or methodology account for the most variation in factor structures from one lexical study to another.

\section{Do Lexical Studies Lead to Inconsistent Results?}

A potential interpretation of our results is that lexical studies lead to inconsistent factor structures. We believe this is not a good interpretation, however, for three reasons.

First, although it is true that results for the Big Five have been disappointingly inconsistent, lexical studies have led to remarkably consistent results at the one- and two-factor levels. Moreover, this consistency is harmonious with Osgood's studies of the structure of attributes ascribed to a variety of objects, not just human targets, indicating an endogenous cognitive basis.

Second, although the five- to seven-factor models we used were not clearly differentiable with respect to their replicability in Greek, their replicability may be more differentiable in other languages. Greek may be a language in which the outcome in their competition is simply "too close to call," whereas studies in other languages may offer more decisive outcomes.

Third, these competing alternatives - the Big Five, Ashton et al.'s six-factor model, and the ML7 - are systematically related to one another. All three have Conscientiousness and Intellect factors, although they differ in whether an Honesty or a Negative Valence factor is added and in how other affective-interpersonal traits are divided up. This suggests they are variations within some underlying scheme. It may be that factor analysis does not directly reveal this underlying scheme.

Recently Gerard Saucier, independent of these Greek lexical analyses, developed an integrative scheme for five-, six-, and seven-factor models from previous lexical studies (Saucier, 2004). This scheme was developing by assigning each of 500 frequently used person descriptors (from Saucier, 1997) into one category based on the factor within each model on which it had its highest loading. Each category was represented by a combination of three codes, one from each set: I, II, III, IV, and V for the Big Five, H, $\mathrm{E}, \mathrm{X}, \mathrm{A}, \mathrm{C}$, and $\mathrm{O}$ for the six-factor model, and gr, sa, et, cf, nv, co, and ov for the ML7 (see Appendix for a key to the abbreviations). For example, friendly loaded most highly on Big Five 


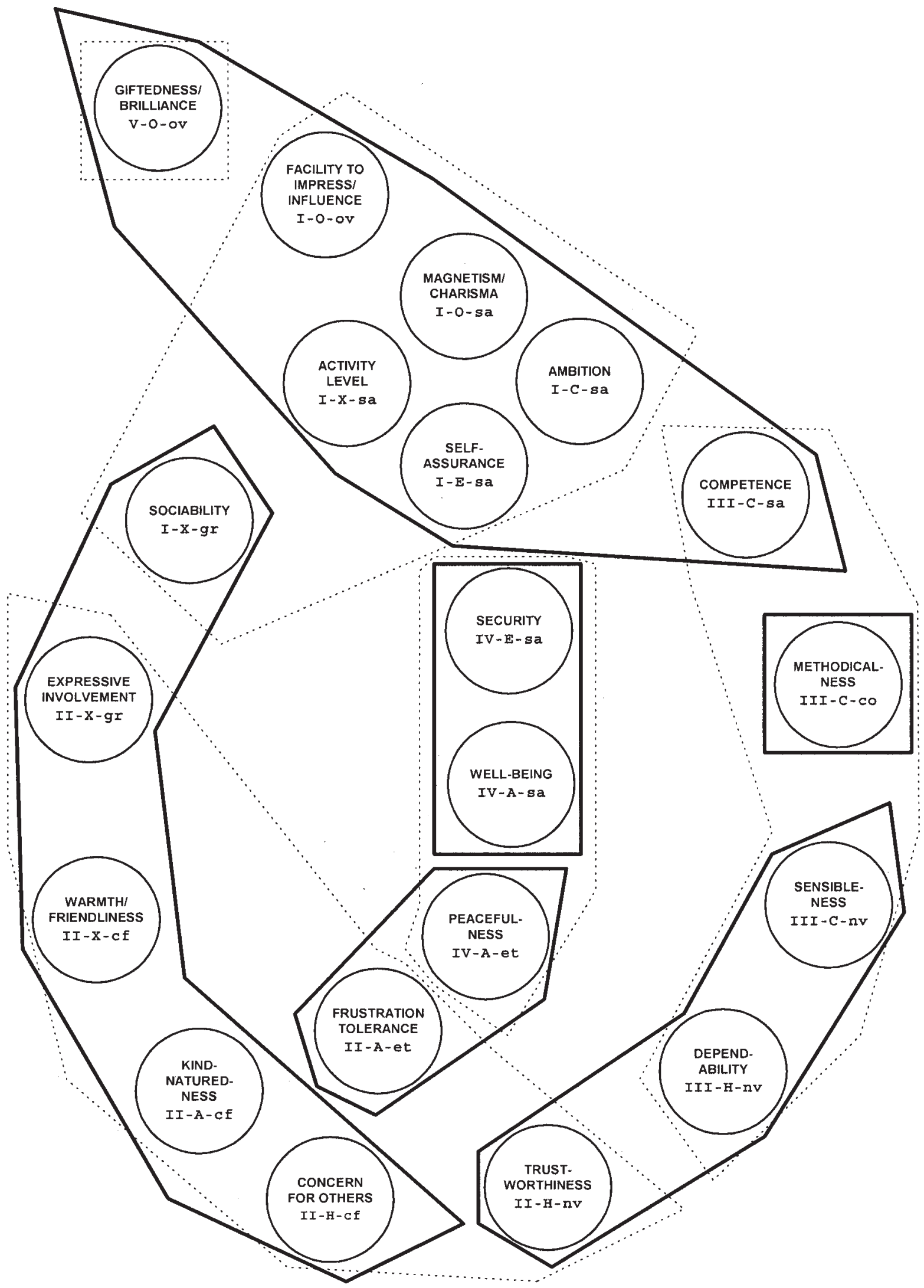

Figure 4. Six Greek emic factors (solid lines) and Big Five (dashed lines) plotted with respect to 20 content clusters. NV = Negative Valence; ML7 = Multi-Language Seven. 
Agreeableness (II), six-factor Extraversion (X), and ML7 Concern for Others (cf), placing it in the II-X-cf category. Utilizing 19 categories having at least three terms, and thereby accounting in total for almost $80 \%$ of the terms, the representation of clusters in Figure 4 was developed. It includes a 20th category (II-X-gr) added to complete the circle that is central to the figure and interpreted as "Expressive Involvement" on the basis of patterns of correlations with questionnaire scales. The circle in the figure corresponds closely to that defined in the double-cone model of Peabody and Goldberg (1989) and the Non-Evaluative Personality Circumplex of Saucier, Ostendorf, and Peabody (2001). Clusters adjacent to each other in the figure contained adjectives that had their highest loading on the same factor in two of the three models and, thus, that in new studies are more likely to fall on the same factor than are those more distant.

The application of this 20-clusters scheme to the Greek results is illuminating. As noted above, the Greek six-factor structure has two anomalous aspects with respect to previous five-, six-, and seven-factor models: A Prowess/Heroism factor and an Agreeableness/Positive Affect factor. These are not anomalies within the 20-clusters scheme. As the solid-line groupings indicate, Prowess/ Heroism represents a novel combination of the clusters at the top of the figure (from Security up to Brilliance and from Activity Level across to Competence). As for Agreeableness/Positive Affect, it can be found at the bottom left of the figure, as a novel combination of clusters from Warmth/Friendliness to Concern for Others. The dotted lines indicate the alternative Big-Five organization of the same 20 clusters. Against the backdrop of this cluster representation, it is clear that the Big Five and the Greek Six differ not merely in arbitrary rotational positions but also in the relative breadth versus narrowness of the factors.

With respect to personality attributes, it is inevitable that the lexicon of one language will have different content emphases than will that of another language, especially with respect to the most frequently used terms. When a particular kind of content (e.g., Competence, or Well-Being) is relatively unrepresented in a lexicon, that content will not provide the dense aggregation of terms necessary to define a factor, and thus, it is likely to be located in the interstitial areas between factors. When a particular kind of content is very heavily emphasized in the lexicon (e.g., Intelligence in English compared to Greek), that content is likely to lead to the location of a factor in that region of descriptive space. If emic trait structures appear inconsistent, it may be because differences in culture lead to differences in the optimal variable selection from that culture's language, which then translate themselves into differences in factor locations. However, an integrative scheme like the 20 clusters enables us to see the order hidden in what may appear to be inconsistent factor analytic results.

\section{Summary and Conclusions}

We extracted person-descriptive terms from a Greek dictionary and reduced these terms to a subset of 400 frequently used person descriptors. We compared factor structures from this variable selection with those from person descriptors rated as having high clarity and found that solutions of one or two factors were invariant whether in original or ipsatized data. Structures of four or five ipsatized-data factors, or three or six original-data factors, were also somewhat invariant across variable selections. Using a crite- rion of factor stability across subsamples, we found that, again, one- and two-factor solutions were by far the most invariant, but here also the five-factor ipsatized-data solution and the six-factor original-data solution had relatively high factor stability. Inspection of these latter solutions indicated that they were in fact very similar, differing mainly in that one of the ipsatized-data factors split into two of the original-data factors. Accordingly, we judged these closely related solutions, along with the broader level oneand two-factor solutions, to be the optimal emic solutions.

We imposed a variety of candidate lexical-factor-structure models and compared them for their degree of replication. One- and two-factor models replicated best. This is unsurprising because these models have consistently replicated in previous lexical studies. ML7 and six-factor model structures were replicated to a much more modest degree, as were Big-Five and Big-Seven models. There was little difference in the overall degree of replication between the various five, six, and seven-factor models.

These findings suggest there may not be a universal set of lexical factors beyond the broad one- and two-factor levels. Structures with more than two factors may differ from one language to another, although there may be similarities among groups of languages with similar linguistic, cultural, or geographic/historical backgrounds.

Although the first systematic attempts to describe human personality were made by Greeks, prior to this report there has been no scientific taxonomy of personality descriptors in the Greek language. The studies reported here come at a critical juncture, when there is a need for studies to compare the replicability of Big-Five structures with alternative competitor structures. Our comparisons led to results that may be surprising to many. It is at levels of factor broader than the Big Five that one finds the most universal and replicable models. At the level of five to seven factors, it seems a more difficult matter to establish what is the most universal or replicable model. For models with this degree of differentiation, much may depend on the region or cultural or language group under study.

\section{References}

Allport, G. W., \& Odbert, H. S. (1936). Trait-names: A psycho-lexical study. Psychological Monographs, 47(Whole No. 211).

Almagor, M., Tellegen, A., \& Waller, N. (1995). The Big Seven model: A cross-cultural replication and further exploration of the basic dimensions of natural language of trait descriptions. Journal of Personality and Social Psychology, 69, 300-307.

Angleitner, A., Ostendorf, F., \& John, O. P. (1990). Towards a taxonomy of personality descriptions in German: A psycho-lexical study. European Journal of Personality, 4, 89-118.

Ashton, M. C., Lee, K., Perugini, M., Szarota, P., De Vries, R. E., Di Blas, L., et al. (2004). A six-factor structure of personality-descriptive adjectives: Solutions from psycholexical studies in seven languages. Journal of Personality and Social Psychology, 86, 356-366.

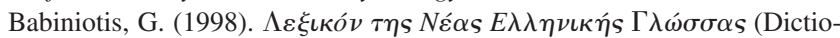
nary of the modern Greek language). Athens, Greece. Dictionary Center.

Benet, V., \& Waller, N. G. (1995). The "Big Seven" model of personality description: Evidence for its cross-cultural generality in a Spanish sample. Journal of Personality and Social Psychology, 69, 701-718.

Benet-Martínez, V., \& Waller, N. G. (1997). Further evidence for the cross-cultural generality of the Big Seven factor model: Indigenous and imported Spanish personality constructs. Journal of Personality, 65, 567-598. 
Boies, K., Lee, K., Ashton, M. C., Pascal, S., \& Nicol, A. A. M. (2001). The structure of the French Personality Lexicon. European Journal of Personality, 15, 277-295.

Browne, M. W., Cudeck, R., Tateneni, K., \& Mels, G. (2002). CEFA: Comprehensive exploratory factor analysis (Version 1.10). Unpublished manual, The Ohio State University.

Caprara, G. V., Barbaranelli, C., \& Zimbardo, P. G. (1997). Politicians' uniquely simple personalities. Nature, 385, 493.

Caprara, G. V., \& Perugini, M. (1994). Personality described by adjectives: The generalizability of the Big Five to the Italian lexical context. European Journal of Personality, 8, 357-369.

Cattell, R. B. (1943). The description of personality. II. Basic traits resolved into clusters. Journal of Abnormal and Social Psychology, 38, 476-507.

Church, A. T., Katigbak, M. S., \& Reyes, J. A. S. (1998). Further exploration of Filipino personality structure using the lexical approach: Do the Big Five or Big Seven dimensions emerge? European Journal of Personality, 12, 249-269.

Church, A. T., Reyes, J. A. S., Katigbak, M. S., \& Grimm, S. D. (1997). Filipino personality structure and the Big Five model: A lexical approach. Journal of Personality, 65, 477-528.

Dabady, M., Bell, M., \& Kihlstrom, J. F. (1999). Person memory: Organization of behaviors by traits. Journal of Research in Personality, 33, 369-377.

De Raad, B., Hendriks, A. A. J., \& Hofstee, W. K. B. (1992). Towards a refined structure of personality traits. European Journal of Personality, 6, 301-319.

DeYoung, C. G., Peterson, J. B., \& Higgins, D. M. (2002). Higher-order factors of the Big Five predict conformity: Are there neuroses of health? Personality and Individual Differences, 33, 533-552.

Di Blas, L., \& Forzi, M. (1998). An alternative taxonomic study of personality-descriptive adjectives in the Italian language. European Journal of Personality, 12, 75-101.

Di Blas, L., \& Forzi, M. (1999). Refining a descriptive structure of personality attributes in the Italian language: The abridged Big Three circumplex structure. Journal of Personality and Social Psychology, 76, 451-481.

Digman, J. M. (1990). Personality structure: Emergence of the five-factor model. In M. R. Rosenzweig \& L. W. Porter (Eds.), Annual review of psychology (Vol. 41, pp. 417-440). Palo Alto, CA: Annual Reviews.

Digman, J. M. (1997). Higher order factors of the Big Five. Journal of Personality and Social Psychology, 73, 1246-1256.

Dunlap, W. P., \& Cornwell, J. M. (1994). Factor analysis of ipsative measures. Multivariate Behavioral Research, 29, 115-126.

Goldberg, L. R. (1981). Language and individual differences: The search for universals in personality lexicons. In L. Wheeler (Ed.), Review of personality and social psychology (Vol. 2, pp. 141-165). Beverly Hills, CA: Sage.

Goldberg, L. R. (1990). An alternative description of personality: The Big-Five factor structure. Journal of Personality and Social Psychology, 59, 1216-1229.

Goldberg, L. R. (1992). The development of markers for the Big-Five factor structure. Psychological Assessment, 4, 26-42.

Goldberg, L. R. (1993). The structure of phenotypic personality traits. American Psychologist, 48, 26-34.

Goldberg, L. R., \& Somer, O. (2000). The hierarchical structure of common Turkish person-descriptive adjectives. European Journal of Personality, 14, 497-531.

Gray, J. A. (1986). Anxiety, personality, and the brain. In A. Gale \& J. A. Edwards (Eds.), Physiological correlates of human behaviour: Vol. 3. Individual differences and psychopathology (pp. 31-43). San Diego, CA: Academic Press.

Hahn, D. W., Lee, K., \& Ashton, M. C. (1999). A factor analysis of the most frequently used Korean personality trait adjectives. European Journal of Personality, 13, 261-282.

Hogan, R. (1983). A socioanalytic theory of personality. In M. M. Page (Ed.), Nebraska Symposium on Motivation (pp. 336-355). Lincoln: University of Nebraska Press.

Hrebickova, M. (1995). The structural model of personality based on the lexical analysis: A Czech replication study of the five-factor model based on a comprehensive taxonomy of personality-descriptive adjectives. Unpublished report, Institute of Psychology, Academy of Sciences of the Czech Republic, Brno.

Hřebíčková, M., Ostendorf, F., Osecká, L., \& Čermák, I. (1999). Taxonomy and structure of Czech personality-relevant verbs. In I. Mervielde, I. J. Deary, F. De Fruyt, \& F. Ostendorf (Eds.), Personality psychology in Europe (Vol. 7, pp. 51-65). Tilburg, The Netherlands: Tilburg University Press.

John, O. P. (1990). The "Big Five" factor taxonomy: Dimensions of personality in the natural language and in questionnaires. In L. A. Pervin (Ed.), Handbook of personality: Theory and research (pp. 66-100). New York: Guilford Press.

McCrae, R. R., \& Costa, P. T., Jr. (1997). Personality trait structure as a human universal. American Psychologist, 52, 509-516.

Norman, W. T. (1963). Toward an adequate taxonomy of personality attributes: Replicated factor structure in peer nomination personality ratings. Journal of Abnormal and Social Psychology, 66, 574-583.

Osgood, C. E., May, W., \& Miron, M. (1975). Cross-cultural universals of affective meaning. Urbana: University of Illinois Press.

Ostendorf, F. (1990). Sprache und Personlichkeitsstruktur: Zur Validitat des Funf-Faktoren-Modells der Personlichkeit [Language and personality structure: Towards the validity of the Five-Factor Model of Personality]. Regensburg, Germany: Roderer.

Paulhus, D. L., \& John, O. P. (1998). Egoistic and moralistic biases in self-perception: The interplay of self-descriptive styles with basic traits and motives. Journal of Personality, 66, 1025-1060.

Peabody, D., \& De Raad, B. (2002). The substantive nature of psycholexical personality factors: A comparison across languages. Journal of Personality and Social Psychology, 83, 983-997.

Peabody, D., \& Goldberg, L. R. (1989). Some determinants of factor structures from personality descriptors. Journal of Personality and Social Psychology, 57, 552-567.

Saucier, G. (1994). Mini-Markers: A brief version of Goldberg's unipolar Big-Five markers. Journal of Personality Assessment, 63, 506-516.

Saucier, G. (1997). Effects of variable selection on the factor structure of person descriptors. Journal of Personality and Social Psychology, 73, $1296-1312$.

Saucier, G. (2002a). Orthogonal markers for orthogonal factors: The case of the Big Five. Journal of Research in Personality, 36, 1-31.

Saucier, G. (2002b). What is more replicable than the Big Five? Broader factors found in English-language personality adjectives. Unpublished manuscript.

Saucier, G. (2003a). An alternative multi-language structure for personality attributes. European Journal of Personality, 17, 179-205.

Saucier, G. (2003b). Factor structure of English-language personality typenouns. Journal of Personality and Social Psychology, 85, 695-708.

Saucier, G. (2004). An integrative framework for factor structures based on personality lexicons. Unpublished manuscript, University of Oregon.

Saucier, G., \& Goldberg, L. R. (2001). Lexical studies of indigenous personality factors: Premises, products, and prospects. Journal of Personality, 69, 847-879.

Saucier, G., \& Goldberg, L. R. (2002). Assessing the Big Five: Applications of 10 psychometric criteria to the development of marker scales. In B. De Raad \& M. Perugini (Eds.), Big Five assessment (pp. 29-58). Goettingen, Germany: Hogrefe \& Huber.

Saucier, G., Ostendorf, F., \& Peabody, D. (2001). The non-evaluative 
circumplex of personality adjectives. Journal of Personality, 69, 537582 .

Saucier, G., \& Simonds, J. (2005). Replication of personality factor structures at the individual level. Manuscript in preparation.

Shweder, R. A. (1972). Semantic structure and personality assessment. Unpublished doctoral dissertation, Harvard University.

Somer, O., \& Goldberg, L. R. (1999). The structure of Turkish traitdescriptive adjectives. Journal of Personality and Social Psychology, 76, 431-450.

Szarota, P. (1996). Taxonomy of the Polish personality-descriptive adjectives of the highest frequency of use. Polish Psychological Bulletin, 27, 343-351.

Szirmak, Z., \& De Raad, B. (1994). Taxonomy and structure of Hungarian personality traits. European Journal of Personality, 8, 95-118.

Tellegen, A. (1985). Structures of mood and personality and their relevance to assessing anxiety with an emphasis on self-report. In A. H. Tuma \& J. D. Maser (Eds.), Anxiety and the anxiety disorders (pp. 681-706). Hillsdale, NJ: Erlbaum

Tellegen, A., \& Waller, N. G. (1987, August-September). Re-examining basic dimensions of natural language trait descriptors. Paper presented at the 95th Annual Convention of the American Psychological Association, New York.

ten Berge, J. M. F. (1999). A legitimate case of component analysis of ipsative measures, and partialling the mean as an alternative to ipsatization. Multivariate Behavioral Research, 34, 89-102.

Tupes, E. C., \& Christal, R. E. (1961). Recurrent personality factors based on trait ratings (USAF ASD Tech. Rep. No. 61-97). Lackland Air Force Base, TX: U.S. Air Force.

White, G. M. (1980). Conceptual universals in interpersonal language. American Anthropologist, 82, 759-781.

\section{Appendix}

\section{Marker Scale Items (English translation) for Factor Constructs From Previous Studies}

Big Five factors

Extraversion (I):

active, daring, energetic, extraverted versus introvert, quiet, shy (.64)

Agreeableness (II):

cooperative, generous, pleasant, sympathetic, warm versus cold, demanding, rude, selfish, unsympathetic (.63)

Conscientiousness (III): careful, conscientious, organized versus careless, unorganized, unsystematic (.68)

Emotional Stability (IV): anxious, emotional, fearful, insecure, jealous, nervous, touchy (.66)

Intellect (V): complex, creative, intelligent, inventive, philosophical (.48)

\section{Negative Valence and Attractiveness}

Negative Valence:

corrupt, coward, dangerous, disgusting, dishonest, dishonorable, idiot, immoral, vulgar (.70)

Attractiveness:

adorable, cute, desirable, erotic (.76)

Big Seven factors

Positive Valence:

admirable, adorable, excellent, remarkable, wonderful, worthy (.83)

Negative Valence:

dangerous, disgusting, disloyal, perverted (.58)

Positive Emotionality: impulsive, sociable versus loner, quiet, reserved (.49)

Negative Emotionality: anxious, frustrated, nervous versus calm (.57)
Agreeability:

lenient versus fighter, brawler, stubborn, uncompromising (.45)

Conscientiousness: consistent, organized, systematic versus disorganized, untidy (.76)

Conventionality: conservative versus peculiar, rebel, unusual (.46)

\section{Multi-Language Seven factors}

Gregariousness (gr): $\quad$ comical, expressive, sociable versus serious, shy, silent (.52)

Self-Assurance (sa): $\quad$ active, brave, confident versus anxious, coward, fearful, weak (.66)

Even Temper (et): $\quad$ patient versus grouchy, emotional, impatient, jealous, short-tempered (.63)

Concern for Others (cf): generous, humble, sentimental, warm versus egocentric (.48)

Conscientiousness (co): $\quad$ organized, perfectionistic, strict versus unorganized, unsystematic (.65)

Originality/Virtuosity (ov): clever, complex, creative, philosophical, talented (.55)

Negative Valence (nv): corrupt, crazy, stupid versus trustworthy (.45)

Six-Factor Model

Extraversion $(\mathrm{X})$

cheerful, energetic, sociable versus passive, quiet, shy, withdrawn (.58)

Emotionality (E): $\quad$ anxious, emotional, fearful, sensitive, sentimental, vulnerable versus courageous, fearless, independent (.64) 
Agreeableness (A): $\quad$ good-natured, patient, peaceful versus aggressive, short-tempered (.53)

Conscientiousness (C): careful versus irresponsible, lazy, negligent, unorganized (.64)

Openness/Intellect $(\mathrm{O})$ : clever, creative, philosophical, rebel, talented versus obedient, unintellectual (.48)

Honesty/Humility $(\mathrm{H})$ : honest, modest, sincere versus disloyal, greedy, sly, two-faced, unfair (.56)

Big One factor

Clever, patient, responsible, sociable, warm versus corrupt, dishonest, disorganized, vengeful (.58)
Big Two factors

Morality and Social Propriety (S): patient, polite, responsible versus bad-tempered, corrupt, disrespectful, egocentric, harsh immoral (.68)

Dynamism (D):

bold, clever, cute, expressive, funny, sociable versus boring, timid, untalkative (.67)

Note. Entries in parentheses are coding system keys. Coefficients in parentheses are coefficient alpha values.

Received October 9, 2003 Revision received November 23, 2004 Accepted December 15, 2004

\section{Members of Underrepresented Groups: Reviewers for Journal Manuscripts Wanted}

If you are interested in reviewing manuscripts for APA journals, the APA Publications and Communications Board would like to invite your participation. Manuscript reviewers are vital to the publications process. As a reviewer, you would gain valuable experience in publishing. The P\&C Board is particularly interested in encouraging members of underrepresented groups to participate more in this process.

If you are interested in reviewing manuscripts, please write to Demarie Jackson at the address below. Please note the following important points:

- To be selected as a reviewer, you must have published articles in peer-reviewed journals. The experience of publishing provides a reviewer with the basis for preparing a thorough, objective review.

- To be selected, it is critical to be a regular reader of the five to six empirical journals that are most central to the area or journal for which you would like to review. Current knowledge of recently published research provides a reviewer with the knowledge base to evaluate a new submission within the context of existing research.

- To select the appropriate reviewers for each manuscript, the editor needs detailed information. Please include with your letter your vita. In your letter, please identify which APA journal(s) you are interested in, and describe your area of expertise. Be as specific as possible. For example, "social psychology" is not sufficient-you would need to specify "social cognition" or "attitude change" as well.

- Reviewing a manuscript takes time (1-4 hours per manuscript reviewed). If you are selected to review a manuscript, be prepared to invest the necessary time to evaluate the manuscript thoroughly.

Write to Demarie Jackson, Journals Office, American Psychological Association, 750 First Street, NE, Washington, DC 20002-4242. 